\title{
Hydrographic conditions in the Brazil-Malvinas Confluence during austral summer 1990
}

\author{
Christine Provost and Slim Gana \\ Centre National de la Recherche Scientifique, Laboratoire d'Océanographie Dynamique et de Climatologie \\ Université Pierre et Marie Curie, Paris
}

\author{
Véronique Garçon, Keitapu Maamaatuaiahutapu, and Matthew England \\ Centre National de la Recherche Scientifique, Unité Mixte de Recherche 39, Toulouse, France
}

\begin{abstract}
The Confluence 3 cruise during February 1990 provides the first hydrographic survey of the Brazil-Malvinas Confluence region ever obtained with such a refined spatial resolution over the continental slope. The closely spaced stations on the slope permit the observation of the branching of the Malvinas Current near $40^{\circ} \mathrm{S}$. The eastern branch returns south, while the eastern one is squeezed along the continental slope, managing to continue northward as far north as $36.3^{\circ} \mathrm{S}$. The BrazilMalvinas (B-M) front has a north-south orientation on the slope and an east-west direction offshore. The B-M front is marked by very strong gradients in temperature and salinity. Fine scale vertical structures and intrusions are numerous in the vicinity of the front and cover a wide range of scales. The largest intrusion observed is a 50$\mathrm{km}$-wide, 350-m-thick subsurface lense of Thermocline Water present on the Malvinas side of the front. The fine scale vertical structure results in very high temperature and salinity fluxes across the front of the order of $2 \times 10^{-2 \circ} \mathrm{C} \mathrm{m}^{-1} \mathrm{~s}^{-1}$ and $10^{-3} \mathrm{psu} \mathrm{m}^{-1}$ $\mathrm{s}^{-1}$. Two types of mode waters are identified as follows: Subtropical Mode Waters north of the front and Subantarctic Mode Waters on both sides of the front. The Subantarctic mode waters (SAMW) appear to recirculate near the western boundary. A young variety of SAMW (lighter, very oxygenated) propagates northward along the continental slope with the Malvinas Current. It detaches from the coast near $37^{\circ} S$ and is strongly altered in the frontal region. It is then entrained southward with the Malvinas return flow and Brazil Current extension. The Confluence 3 hydrographic survey provides a good description of the North Atlantic Deep Water (NADW) and Circumpolar Deep Water (CDW) convergence near the western boundary. Strong, fine scale vertical structures are observed in the vicinity of the NADW/CDW front, and the associated temperature and salinity fluxes induced are strong, $5 \times 10^{-30} \mathrm{~cm} / \mathrm{s}$ and $2 \times$ $10^{-3} \mathrm{psu} . \mathrm{m} / \mathrm{s}$, respectively.
\end{abstract}

\section{Introduction}

Because of its active exchanges with neighboring oceans, the South Atlantic Ocean plays a crucial role in the global climate system. To gain a better understanding of its role, several international programs have been and are currently being carried out. Among them, the pre-World Ocean Circulation Experiment (WOCE) Confluence Program was designed to study the western boundary of the South Atlantic [Confluence Group, 1990]. This program is a joint Argentine, French, and U.S. effort to study the dynamics of the southwestern Atlantic Ocean. It concentrates on the Brazil and Malvinas Currents along the coast of Argentina and Uruguay.

The Brazil-Malvinas Confluence is a highly dynamic region. Two major currents, the Brazil and Malvinas Currents, with strongly contrasting water types (warm and salty for the Brazil Current and cold and fresh for the Malvinas Current) meet in this zone, generating a strong frontal structure and a

Copyright 1995 by the American Geophysical Union.

Paper number 94JC02864.

0148-0227/95/94JC-02864\$05.00 complex array of eddies, rings, and filaments [Gordon, 1989]. The confluence region is at the crossroads of several major water masses of the world ocean, and the thermohaline stratification is particularly rich and complex. Reid et al. [1977] identify seven distinct water masses below the seasonal thermocline from the vertical distributions of the temperature, salinity, dissolved oxygen, and nutrients. Maamaatuaiahutapu et al. [1992, 1994] produce a quantitative water mass analysis of the region using the hydrographic data from the first and second cruises of the confluence program. They document the source water type proportions at two different seasons. They show that the upper, intermediate, and even deep waters undergo great spatial changes between spring and winter. Except at the lowest level of the Weddell Sea Deep Water, the deep waters are subjected to considerable variation in location. These changes in location appear to be influenced by the movement of the thermocline front.

This paper presents the hydrographic conditions observed during the austral summer of 1990 by the Confluence 3 cruise on board the Research Vessel Le SUROIT. It is the first time, in that region, that hydrographic data cover the conti- 


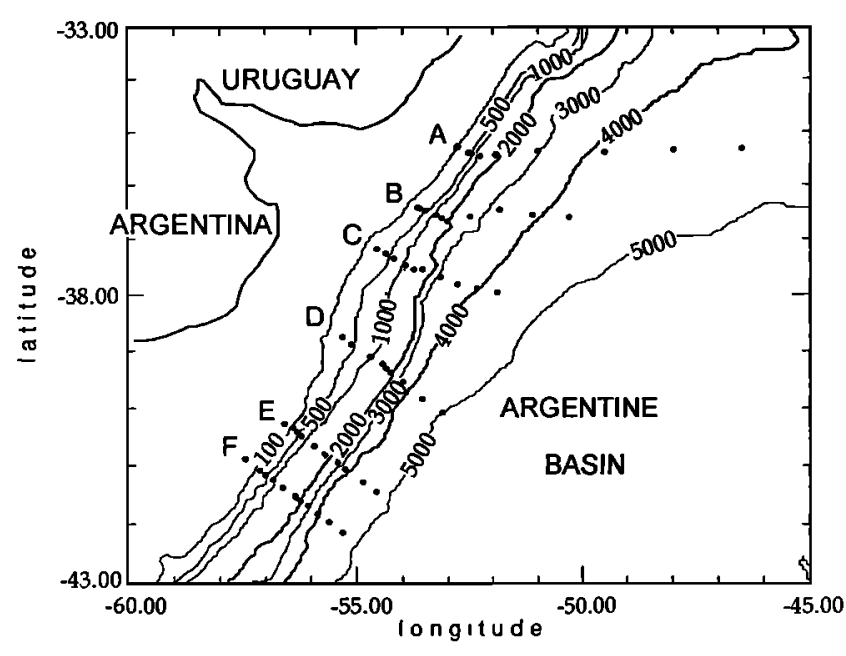

CONFLUENCE 3

Figure 1. Confluence 3 conductivity-temperature-depth (CTD) $-\mathrm{O}_{2}$ station locations. The sections are labeled A, B, C, D, E, F from north to south.

nental slope from a depth of $100 \mathrm{~m}$ to over $4000 \mathrm{~m}$ with such a fine horizontal resolution and with continuous dissolved oxygen profiles. We first present the data and their temperature/salinity/dissolved oxygen $\left(\theta / \mathrm{S} / \mathrm{O}_{2}\right)$ diagrams (section 2). The $\mathrm{S} / \mathrm{O}_{2}$ and $\theta / \mathrm{O}_{2}$ diagrams bring a new and useful illustration of the water mass characteristics. We then perform a quantitative water mass analysis of the upper and intermediate layers, which quantifies the geographical distribution of the water masses in the upper $1000 \mathrm{~m}$ (section 3.1). We can resolve the relatively narrow flows of the Brazil and Malvinas Currents upstream and downstream of their confluence. The widespread presence of the Rio de La Plata Water, even far away from the coast, and the northward extent of the Malvinas Current along the slope are surprising. The Brazil-Malvinas front is well resolved on two sections; intrusions are described and the associated mixing calculated (section 3.2). Mode waters are identified by the associated minimum of potential vorticity; they appear to recirculate near the western boundary (section 3.3). The Confluence 3 hydrographic survey provides a good description of the deep water structure near the western boundary, and mixing at the North Atlantic Deep Water and Circumpolar Deep Water convergence is estimated (section 4).

\section{Data}

\subsection{Observations}

The Confluence 3 cruise took place during the austral summer of 1990 (February 7-27) on board the RV Le SUROIT from Institut Français de Recherche pour l'Exploitation de la Mer (IFREMER). The locations of the 61 conductivity-temperature-depth (CTD) $-\mathrm{O}_{2}$ stations performed during the cruise are shown in Figure 1. These stations are distributed along six east-west sections located between $43^{\circ} \mathrm{S}$ and $35^{\circ} \mathrm{S}$ and oriented perpendicularly to the continental slope. The cruise took place in two legs: the two southernmost sections (stations 1 to 22) were realized during the first leg (February 7-14), whereas the four northern sections (stations 23 to 61) were completed during the second leg (February 16-27). Along each section the ba- thymetry varied from about 100 to over $4300 \mathrm{~m}$. At each station the CTD-O $\mathrm{O}_{2}$ probe went as close as possible to the bottom. The distance between two successive stations has an average of $22 \mathrm{~km}$ and is reduced above the continental slope in order to avoid differences in bathymetry greater than $500 \mathrm{~m}$ between neighboring stations. Twenty-seven stations out of the 61 went to depths over $3300 \mathrm{~m}$.

We used a Neil Brown Mark II CTD-O $\mathrm{O}_{2}$ probe equipped with a 12 Niskin bottle General Oceanic rosette. The samples were collected during the ascending profiles, and $8 \%$ of them were taken at depths greater than $3000 \mathrm{~m}$. Salinity was determined using a Guildline salinometer G8400. Dissolved oxygen concentrations were measured with a titroprocessor Methron according to the Winkler method.

The quality of the temperature, salinity, oxygen, and pressure data during the Confluence 3 fulfills the WOCE Hydrographic Program requirements [Provost et al., 1991]. However, the quality of the nutrients data does not. Nevertheless, we are confident in the general distribution patterns of nutrient concentrations over the area [Garçon et al., 1991].

\subsection{The $\mathrm{O} / \mathrm{S} / \mathrm{O}_{2}$ Characteristics of the Region}

Although only 9 of the 61 stations reached deeper than $4400 \mathrm{~m}$, all of the water masses previously identified [Reid et al., 1977] in the area were encountered. Below the seasonal thermocline, Reid et al. [1977] identify seven distinct core layers by local extrema in one or several of the parameters of $\theta, \mathrm{S}, \mathrm{O}_{2}$, or nutrients. These seven core layers are illustrated on the following three vertical sections: the northernmost section $A$ (Figure $2 a$ ), section $C$ in the middle (Figure $2 b$ ), and the southernmost section $F$ (Figure $2 c$ ). The basic water mass structure is also distinct on the $\theta / \mathrm{S}, \mathrm{S} / \mathrm{O}_{2}$, and $\theta / \mathrm{O}_{2}$ diagrams (from data with a decibar resolution) for the whole cruise shown on Figures $3 a, 3 b$, and $3 c$, respectively. The $\theta / \mathrm{O}_{2}$ and $\mathrm{S} / \mathrm{O}_{2}$ diagrams are the first ones obtained in that region.

The $\theta / S$ distribution is relatively tight for waters of $\theta<$ $4^{\circ} \mathrm{C}$, whereas the corresponding parts of the $\theta / \mathrm{O}_{2}$ and $\mathrm{S} / \mathrm{O}_{2}$ diagrams are more spread out. The coldest water $\left(\theta-0.186^{\circ} \mathrm{C}\right.$ and $S$ of about 34.672 practical salinity units (psu)) corresponds to the Weddell Sea Deep Water (WSDW) and is encountered below $4500 \mathrm{~m}$. Its oxygen concentration varies from 4.99 to $5.44 \mathrm{~mL} \mathrm{~L}^{-1}$. The highest oxygen concentration is obtained at station 4 (section F).

The Lower Circumpolar Deep Water (LCDW) and Upper Circumpolar Deep Water (UCDW) are characterized by a local minimum in dissolved oxygen that appears on the $\mathrm{S} / \mathrm{O}_{2}$ or $\theta / \mathrm{O}_{2}$ diagrams. The North Atlantic Deep Water (NADW) appears as a local extremum on all three diagrams (Figure 3). The structure in $\theta, S$, and $O_{2}$ of the three sections $A, C$, and $F$ is similar below $1100 \mathrm{dbar}$, the main difference being the pressure range in which the extrema are encountered. The LCDW and UCDW sink as they progress to the north, whereas the NADW rises as it moves southward (Figure 2).

A low-salinity intermediate water mass with a salinity of about 34.1 to $34.3 \mathrm{psu}$ is found with a potential temperature range of $2.5^{\circ}$ to $5^{\circ} \mathrm{C}$ (Figure 3). This Antarctic Intermediate Water (AAIW) has its origin near the Antarctic Polar Front, where it sinks below the Subantarctic Surface Water (SASW) [Piola and Gordon, 1989]. The SASW (also called Malvinas Water (MW)) has $\theta / S$ characteristics close to those of AAIW. The oxygen-salinity diagram permits separation of 


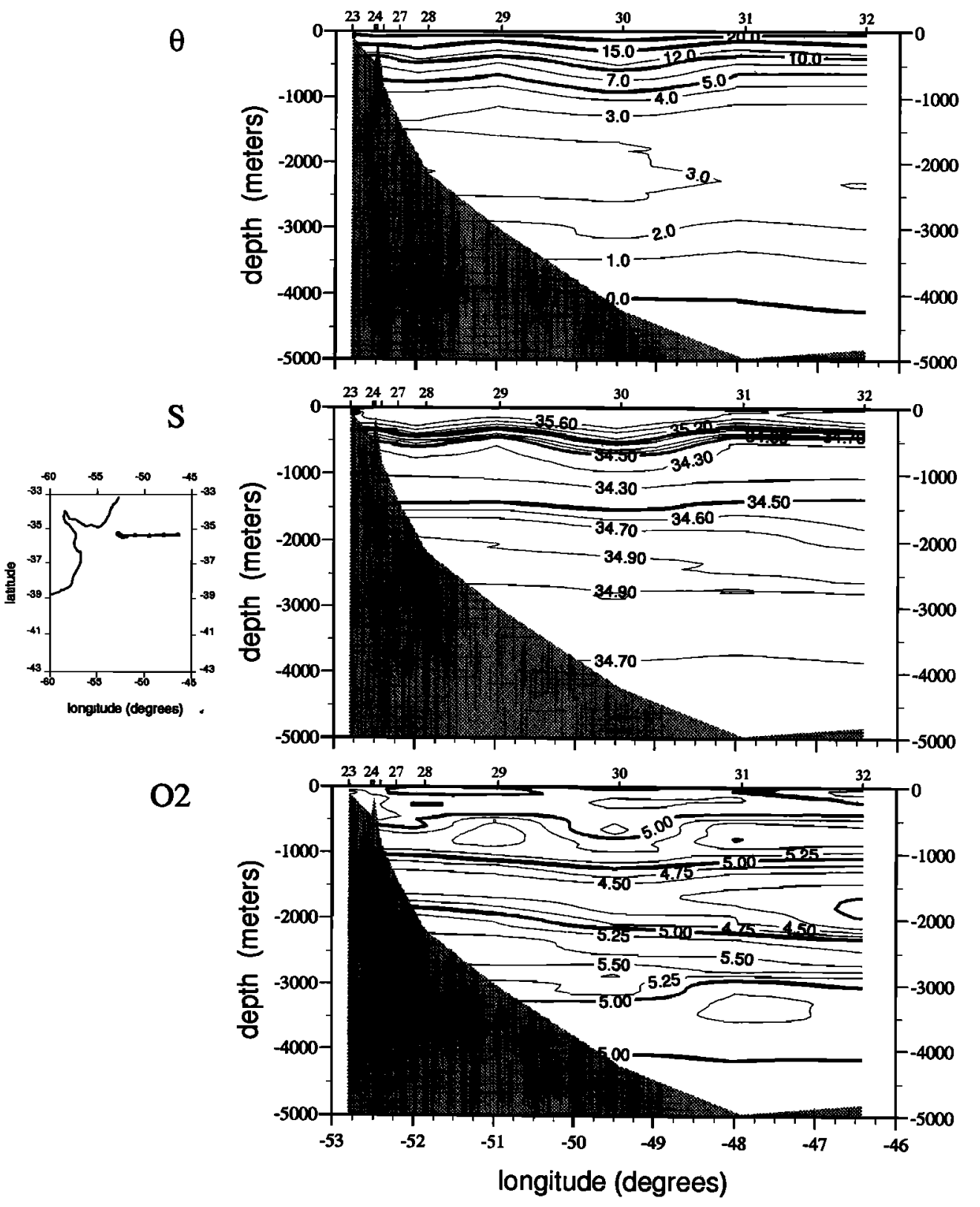

Figure 2a. Temperature, salinity, and dissolved oxygen along sections A.

AAIW and SASW, with higher values for the latter (Figure 3b).

Above the $5^{\circ} \mathrm{C}$ potential temperature (i.e., in the upper layers), the following two strongly contrasting water masses are easily distinguished in the $\theta / S$ diagram in spite of the important scatter: the Thermocline Water (TW) carried by the Brazil Current and the SASW introduced by the Malvinas Current. The TW is characterized by its thermoclinehalocline structure (salinity increasing from 34.3 to 36.2 psu), whereas the Malvinas Water is isohaline (34.10 psu). The isohaline of Malvinas Water extends almost as a vertical line at 34.10 psu over a wide potential temperature range of $2.5^{\circ} \mathrm{C}$ to over $16^{\circ} \mathrm{C}$. This corresponds to Malvinas Water heated superficially in the shallow seasonal thermocline.

Three distinct $\theta / \mathrm{S}$ scatters can be distinguished above the $5^{\circ} \mathrm{C}$ potential temperature (Figure 3). The $\theta / \mathrm{S}$ scatter in the rectangle limited by 33.60 and $34.10 \mathrm{psu}$ and by $5^{\circ}$ and $17^{\circ} \mathrm{C}$ results from the mixing between the Malvinas Water and the so-called "Slope Water" [Gordon, 1981]. The slope surface water is a thin layer of low salinity (less than $34.00 \mathrm{psu}$ ) above the thick, nearly isohaline (about $34.10 \mathrm{psu}$ ) Malvinas Water. The $\theta / \mathrm{S}$ scatter between 5 and $11^{\circ} \mathrm{C}$ and 34.10 and the TW is due to mixing between Malvinas Water and Thermocline Water in the frontal region. The $\theta / S$ plumes at temperature above $17^{\circ} \mathrm{C}$ are provided by data from the very surface of the stations of the three northernmost sections and are due to mixing with fresh water from the Río de La Plata Estuary. The Río de La Plata Water (RLPW) is relatively warm $\left(22^{\circ} \mathrm{C}\right)$ although somewhat cooler than surface water encountered offshore (for example, greater than $24^{\circ} \mathrm{C}$ at stations 29 and 30 ).

The TW and SASW also represent two very distinct branches in the $\mathrm{S} / \mathrm{O}_{2}$ diagram (Figure 3): the $\mathrm{TW}$ branch is situated above the 34.50 psu line, whereas the SASW branch 


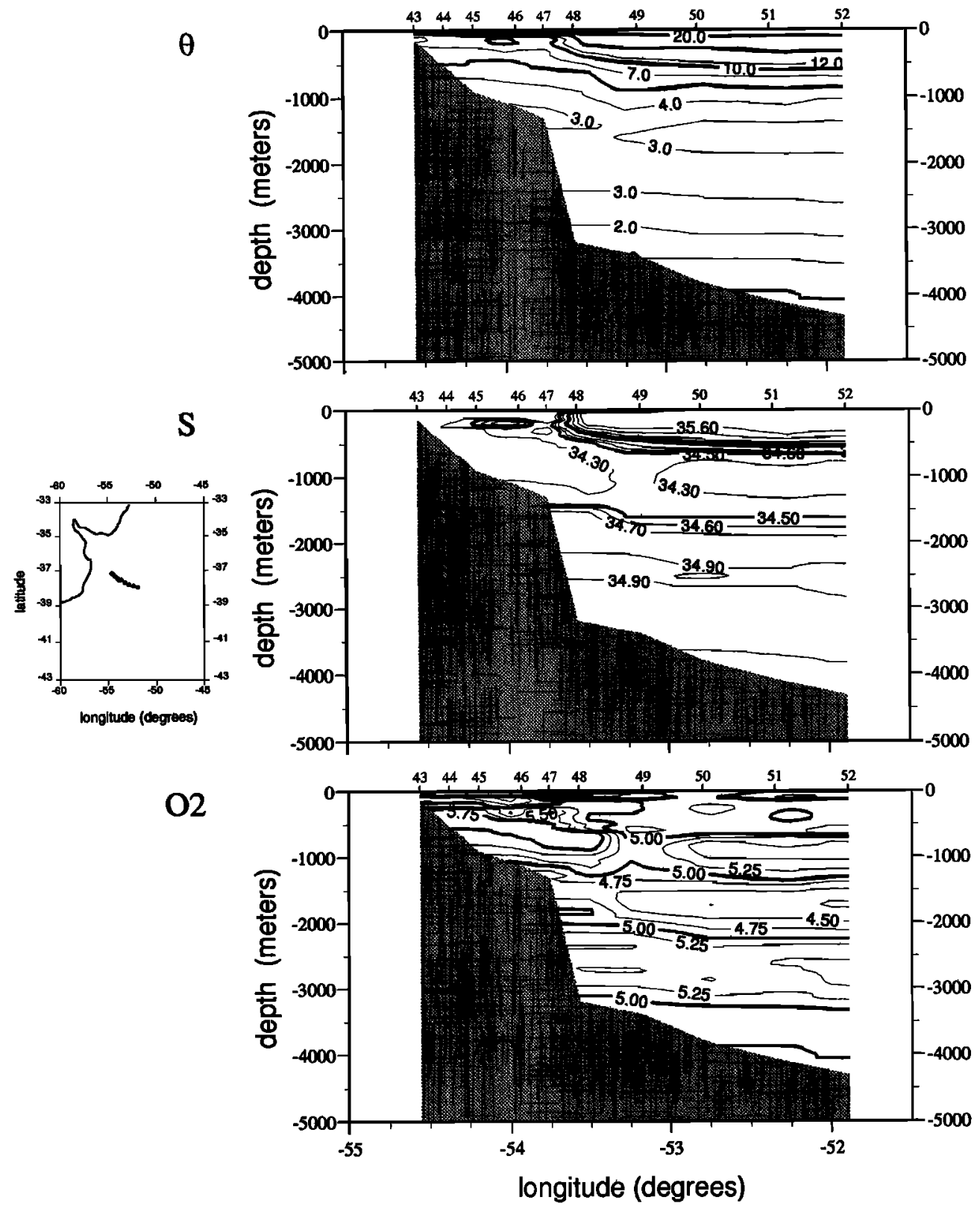

Figure 2b. Same as Figure $2 b$, except for section $C$.

is below 34.20 psu. Fresh water from the Río de La Plata appears as a scatter of very low salinity values. In the $\theta / \mathrm{O}_{2}$ diagram the SASW and the surface water above it have a much higher $\mathrm{O}_{2}$ content than the TW and the water overlying it.

\section{Upper and Intermediate Levels}

\subsection{Synthetic Picture of the Distribution of Water} Masses in the Upper 1000 m During February 1990

An analysis of water masses in the upper layers was performed with an inverse method similar to that described by Maammaatuaiahutapu et al. [1992]. The purpose was to find the mixture of source water types that best describes, in the least squares sense, the composition of a given water sample [Mackas et al., 1987]. Because the quality of the nutrients data is poor during Confluence 3, we did this analysis with only the following three parameters of the CTD: T, S, and $\mathrm{O}_{2}$. The vertical resolution chosen was every 10 dbar. The solution provides the best fitting fractional distribution (percent) of each source water type in the water sample.

To describe the upper $1000 \mathrm{~m}$ of the confluence region, the following four water masses were retained: the Río de La Plata Water (RLPW), the Subantarctic Surface Water (SASW), the Thermocline Water (TW), and the Antarctic Intermediate Water (AAIW). The $\mathrm{T}, \mathrm{S}$, and $\mathrm{O}_{2}$ characteristics for these source water types are given in matrix $A$ (Table 1). The sensitivity and the robustness of the results are investigated through perturbation experiments. One hundred 


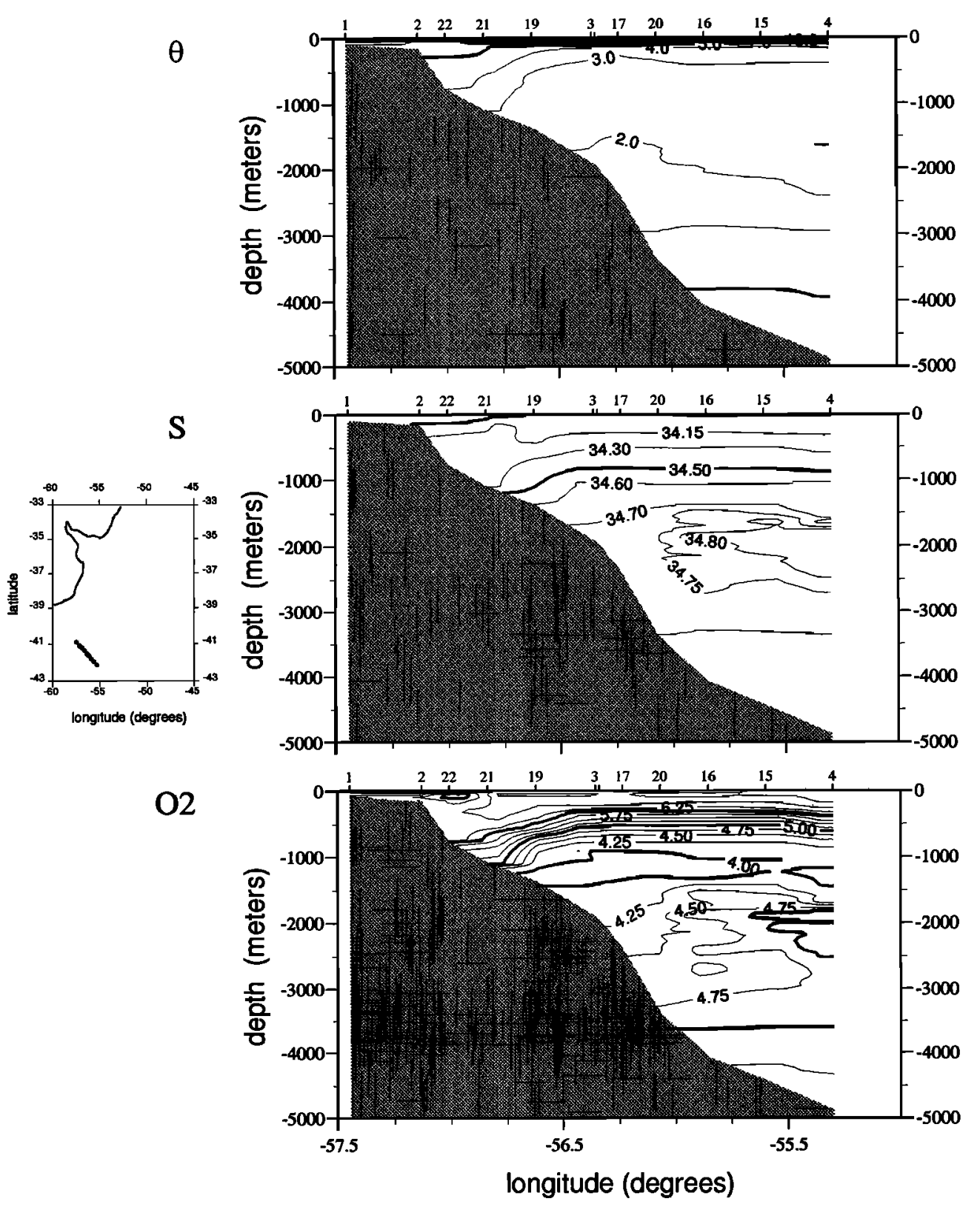

Figure 2c. Same as Figure 2a, except for section F.

random perturbations are made on each source water type of the matrix $A$, and a mean solution is deduced. The sensitivity of each source water type in each sample can be expressed as a standard deviation value, and in the worst case, the results can be assumed accurate to within about $30 \%$. The mixing proportions along the six zonal sections are presented in Figures 4a-4d. As expected, the RLPW (Figure $4 a$ ) is confined to the upper layer, the SASW (Figure $4 \mathrm{~b}$ ) is seen mostly on the southern sections, the TW (Figure 4c) is present only on the three northernmost sections (associated with the Brazil Current), and the AAIW (Figure 4d) is found below those three water masses. This is the classical picture. However, this analysis reveals a few surprising and new features, such as the northward extension of the Malvinas Current.
The results of the inversion have to be critically examined in the upper layer where warmed $\mathrm{TW}$, despite its high salinity, can be mistaken for RLPW (Figure 4a), dissolved oxygen being nondiscriminative between these two water masses. This is particularly clear on section A at station 30 where surface salinities are higher than 36 psu. Another word of caution is necessary for the lower $200 \mathrm{~ms}$, where the AAIW (Figure 4d) found below $800 \mathrm{~m}$ on the southernmost sections is, in fact, a mixture of pure AAIW and UCDW (not introduced into the analysis). The residuals (Figure 4e) reflect these limits of the inversion: large residuals are often found in the upper $70 \mathrm{~m}$ and below $800 \mathrm{~m}$.

The extent of the RLPW as found in this inversion (Figure 4a) is certainly exaggerated. This is particularly evident on section $A$, where warmed TW is considered as RLPW. 


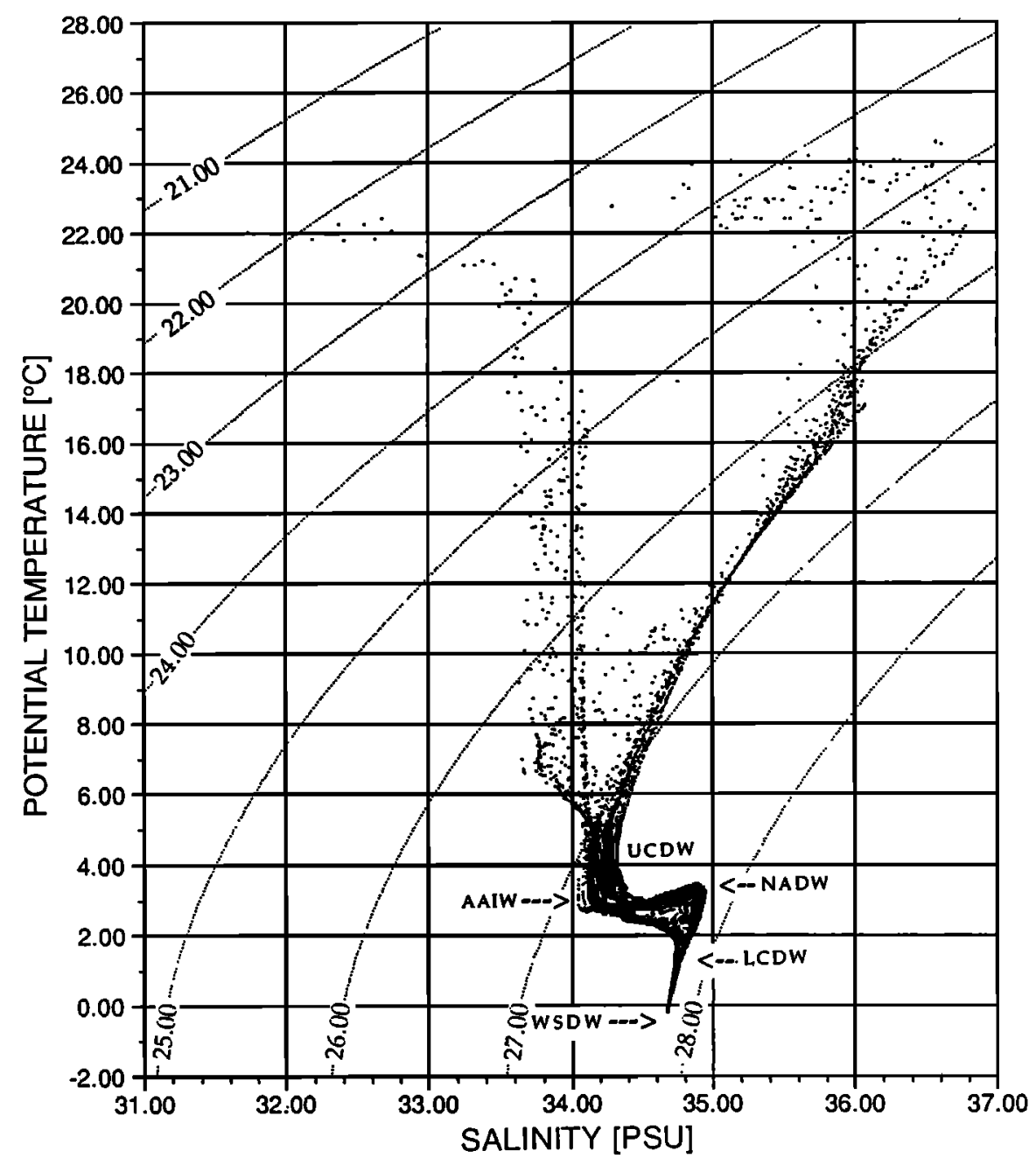

Confluence 3

Stations $1-61$

Figure 3a. Ensemble diagram of the cruise showing $\theta / \mathrm{S}$ distribution. Density curves are referred to $0 \mathrm{dbar}$.

However, the extension of the RLPW obtained on sections $B$ and $C$ agrees with the salinity distribution. The eastward extension of the RLPW is remarkable; it is encountered with concentration greater than $75 \%$ at each easternmost station of sections $B$ and $C$. Its presence is restricted to the upper $20-40 \mathrm{~m}$.

The Malvinas Water (MW) (or Subantarctic Surface Water (SASW)) (Figure 4b) splits into two branches on section D; the eastern branch returns to the south, while the western branch manages to continue northward (sinking below the TW). Indeed, a surprising feature is the narrow vein of Malvinas Water squeezed along the slope as far north as $36.3^{\circ} \mathrm{S}$ (section B). There is no MW present on section $\mathrm{A}$. The depth of the core of the MW deepens from the south to the north: $150-350 \mathrm{~m}$ at $42^{\circ} \mathrm{S}, 200-300 \mathrm{~m}$ at $40.5^{\circ} \mathrm{S}, 200-400 \mathrm{~m}$ at $39.5^{\circ} \mathrm{S}, 300-500$ at $37.5^{\circ} \mathrm{S}$, and $500-700 \mathrm{~m}$ at $36.3^{\circ} \mathrm{S}$.

On section $A$ the upper boundary of the Thermocline Water (Figure 4c) should not be considered, for the model cannot discriminate between the warmed TW and the
RLPW. TW concentration exceeds $75 \%$ in the 100 - to $400-\mathrm{m}$ layer. Within this layer the TW is concentrated in three subsurface lenses with cores between 200 and $300 \mathrm{~m}$. These can be related to the "eddying" nature of the Brazil Current [Roden, 1986]. The Brazil Current is not a broad continuous current; it is made up of a narrow, jetlike flow with predominant wavelike perturbations along its flank. Some of the perturbations develop into warm core eddies and rings, predominantly elliptical in shape, with axes of the order of $100-200 \mathrm{~km}$ and propagation speeds of $0.1-0.2 \mathrm{~m} \mathrm{~s}^{-1}$ [Legeckis and Gordon, 1982]. The wavy TW concentration structure of section A results from a cut through a meandering and eddy-shedding Brazil Current. The westernmost lobe is stuck to the slope. The first subsequent TW lobe is the deepest, warmest, and the poorest in oxygen and represents the first anticyclonic loop of the initial Brazil Current overshoot and retroflection. The two other lobes (westernmost and easternmost) extend to lesser depths, with lower core temperature and salinity, indicating mixing with surrounding 


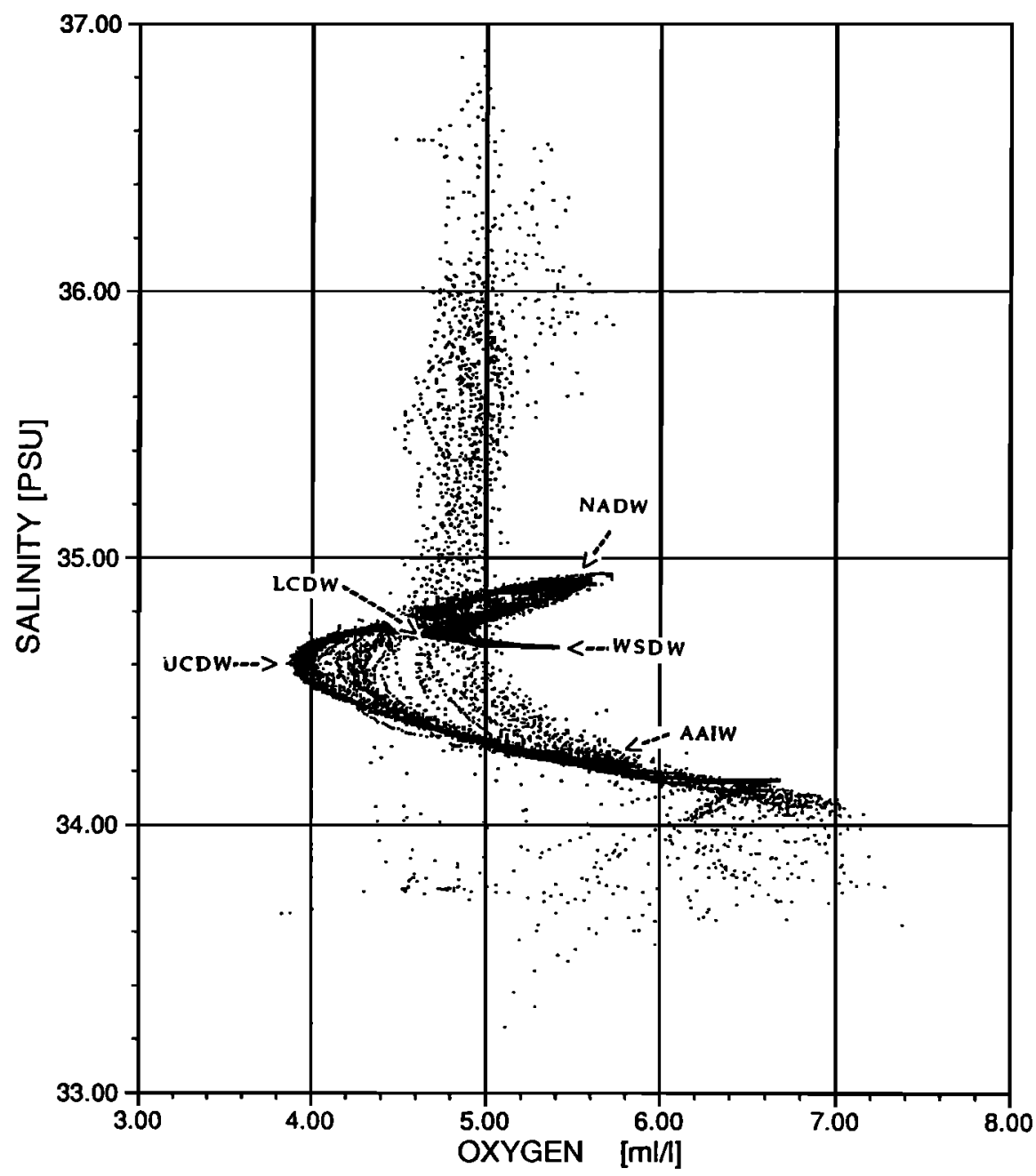

Confluence 3

Stations $1-61$

Figure 3b. Same as Figure 3a, except for $\mathrm{S} / \mathrm{O}_{2}$.

waters. On section A we observe the TW bifurcating into two branches: one continues squeezed along the continental slope and getting mixed with surrounding waters, while the other is the first anticyclonic loop of the initial Brazil overshoot leaving the coast. The easternmost lobe is a second loop. On sections $B$ and $C$ the TW presents concentrations higher than $90 \%$ in a homogeneous layer between 150 and $350 \mathrm{~m}$. The TW lobe along the continental slope has disappeared. The TW has left the coast; it is no longer present on the three southern sections.

The only two sections on which both TW and SASW are present (i.e., the only sections that cross the Brazil-Malvinas front) are sections $B$ and $C$. The Brazil-Malvinas front is located on their western side, relatively close to the continental slope. On those sections the Brazil-Malvinas front has a nearly north-south orientation, then it necessarily turns eastward to be located between sections $C$ and $D$ (Figures 5a-5c).

As mentioned above, only the upper boundary of the
AAIW (Figure 4d) should be considered as realistic, since the AAIW found on sections D, E, and F below $800 \mathrm{~m}$ is a mixture of pure AAIW and UCDW (UCDW is not introduced into the water mass inversion). The AAIW is found at much shallower depths south of the Brazil-Malvinas front, i.e., on sections D, E, and F, than north of the front. Away from the continental slope, the upper boundary of AAIW, for example, the $75 \%$ isoline, deepens by over $400 \mathrm{~m}$ between sections C and D. The TW-AAIW front must occur between sections $C$ and $D$. As observed by Maamatuaiahutapu et al. [1992] with the data of the wintertime cruise of the confluence program, more AAIW is present on section A than on section $C$, this being due to the recirculation of AAIW. Concentrations of AAIW reaching 50\% appear at the boundary between SASW and TW (i.e., at the BrazilMalvinas front) on sections $B$ and $C$ at depths of $200-300 \mathrm{~m}$. This is related to the mixing at the front which results in $\mathrm{T}$, $\mathrm{S}$, and $\mathrm{O}_{2}$ characteristics that the inverse model considers to be a mixture including SASW, TW, and AAIW. This is discussed 


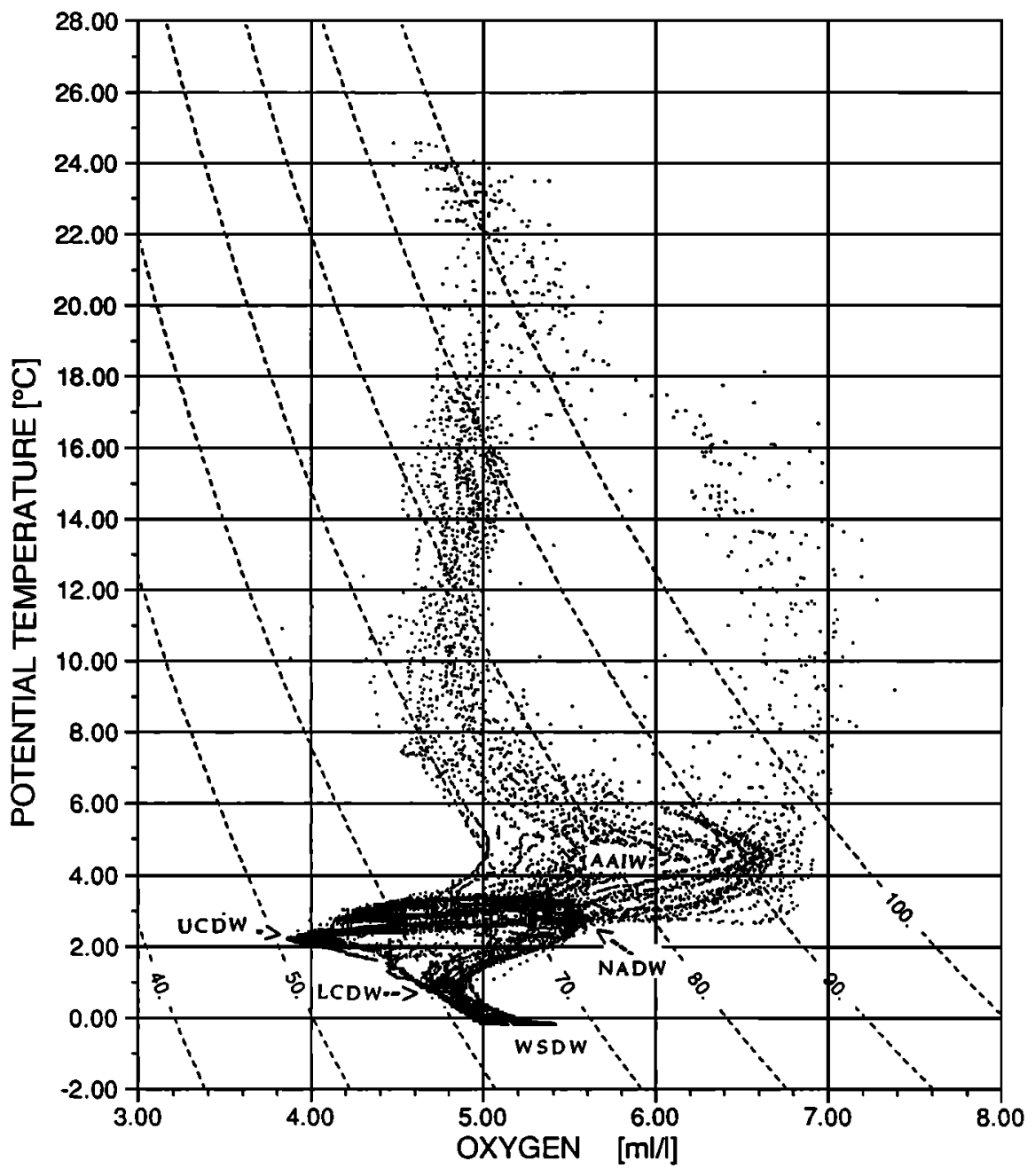

Confluence 3

Stations $1-61$

Figure 3c. Same as Figure a, except for $\theta / \mathrm{O}_{2}$. Oxygen saturation curves are calculated with $\mathrm{S}=35 \mathrm{psu}$.

further in the next section. The upper boundary of the AAIW in section $A$ feels the three lobes of TW discussed above.

\subsection{The Brazil-Malvinas Front and Associated Mixing}

3.2.1. The Brazil-Malvinas front observed in February 1990. The Brazil-Malvinas (B-M) front is seen on two sections (sections $B$ and $C$ ) on the western part close to the continental slope (Figures $5 \mathrm{a}$ and $5 \mathrm{~b}$ ). As a measure of the steepness of the front, we have plotted the vertically integrated temperature and salinity between 50 and $500 \mathrm{~m}$ depth as a function of distance along these two sections (Figure 6). The lower limit $500 \mathrm{~m}$ was chosen in view of the shallowness of stations on the continental slope. On section $B$, station 40 is only $713 \mathrm{~m}$ deep and the front is clearly between stations 40 and 39. The B-M front is very steep. Stations 40 and 39 are separated by $22 \mathrm{~km}$, their vertically averaged temperature and salinity differ by $6.5^{\circ} \mathrm{C}$ and $1.2 \mathrm{psu}$, respectively. On
Table 1. Tracer Characteristics of the Source Water Types and Estimated Standard Deviation for Each Tracer

\begin{tabular}{lcrrrr}
\hline & \multicolumn{4}{c}{ Matrix A } \\
\cline { 2 - 5 } Tracers & $\begin{array}{c}\text { RLPW } \\
(\mathrm{x} 1)\end{array}$ & \multicolumn{1}{c}{$\begin{array}{c}\text { TW } \\
(\mathrm{x} 2)\end{array}$} & $\begin{array}{c}\text { SASW } \\
(\mathrm{x} 3)\end{array}$ & $\begin{array}{c}\text { AAIW } \\
(\mathrm{x} 4)\end{array}$ & $\begin{array}{c}\text { Matrix } \\
\text { W } \sigma\end{array}$ \\
\hline T, ${ }^{\circ} \mathrm{C}$ & 22.0 & 16.0 & 5.0 & 4.0 & 0.25 \\
S, psu & 33.0 & 35.8 & 34.1 & 34.2 & 0.07 \\
$\mathrm{O}_{2}, \mathrm{~mL} / \mathrm{L}$ & 5.0 & 5.4 & 6.0 & 5.6 & 0.13 \\
$\sum_{i} x_{i}=1$ & 1.0 & 1.0 & 1.0 & 1.0 & 0.01 \\
\hline
\end{tabular}

RLPW is Río de La Plata Water, TW is Thermocline Water, SASW is Subantarctic Surface Water, and AAIW is Antarctic Intermediate Water. The (x1) indicates the fraction of RLPW present, (x2), the fraction of TW present, etc. The weighting matrix is derived by inverting the matrix $W=\sigma^{2} I$, where $I$ is the identity matrix. The summation is the sum of $x_{i}$, which is the fraction of water type $i$ present in the sample. (The sum of the fractions must equal 1.) 


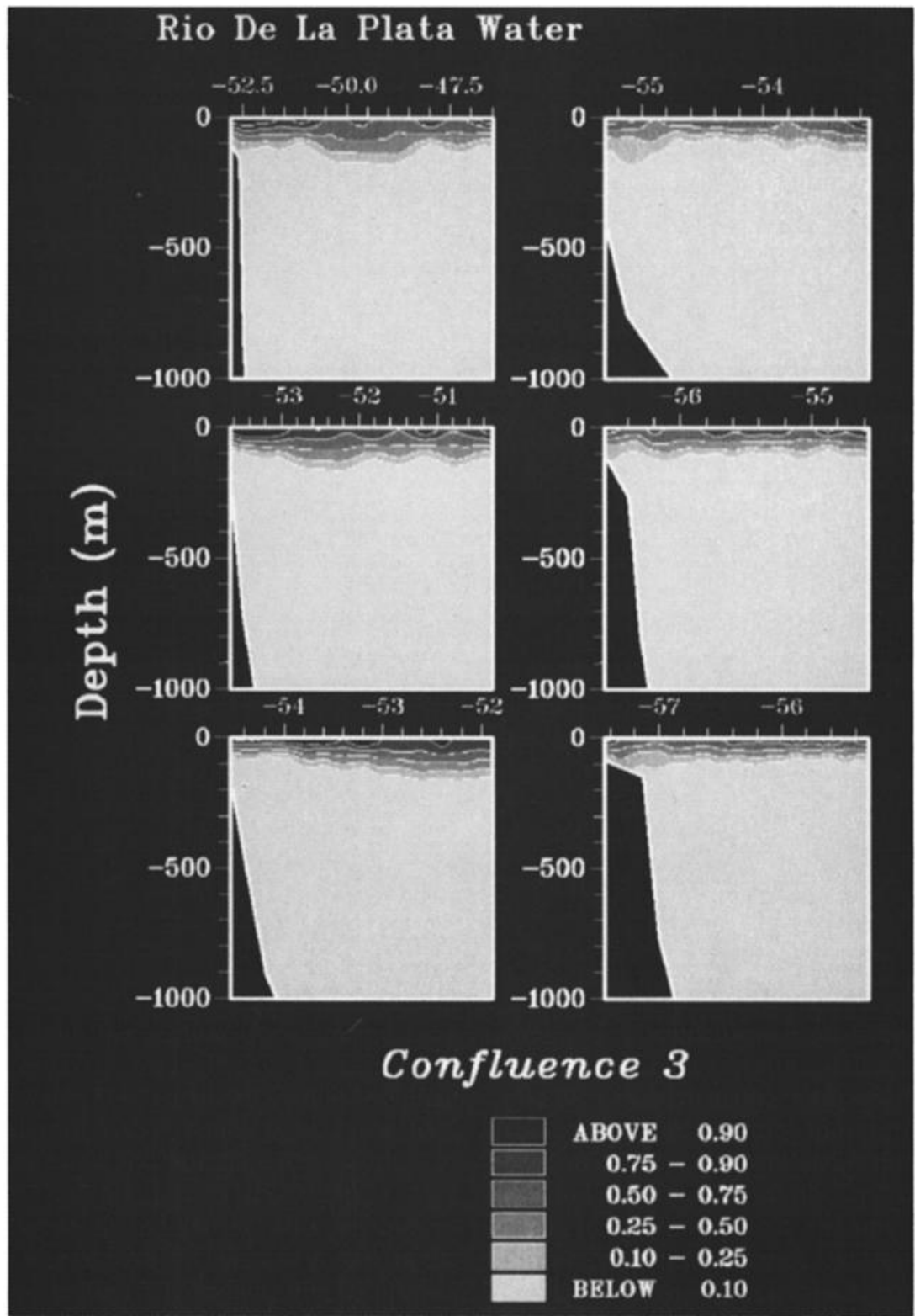

Figure 4a. Water mass proportions for Río de La Plata Water (RLPW).

section $\mathrm{C}$ the front is located slightly offshore between stations 47 and 48 . The distance between the two stations is $14 \mathrm{~km}$, and the difference in vertically averaged temperature and salinity is $6.1^{\circ} \mathrm{C}$ and $1.1 \mathrm{psu}$, respectively.

A notable feature on section $C$ is the bump in $T$ and $S$ (over $1^{\circ} \mathrm{C}$ and 0.2 psu) between stations 44 and 47 , i.e., inshore of the B-M front (Figures $6 \mathrm{c}$ and $6 \mathrm{~d}$ ). This feature extends about $50 \mathrm{~km}$ along the section. It is created by a subsurface lense of relatively high-salinity, high-temperature, and low-oxygen water $\left(34.75 \mathrm{psu}, 10^{\circ} \mathrm{C}\right.$, and less than $4.5 \mathrm{~mL} \mathrm{~L}{ }^{-1}$ compared with SASW which is $34.2 \mathrm{psu}, 6^{\circ} \mathrm{C}$, and $5.2 \mathrm{~mL} \mathrm{~L}^{-1}$ ) (Figures 6a and 6b). The lense with a $\sigma_{t}$ ranging from 26.40 to $27.05 \mathrm{~mL} \mathrm{~L}^{-1}$ is about $350 \mathrm{~m}$ thick residing at depths between 50 and $400 \mathrm{~m}$. This anomaly is considered to be a mixture of SASW, TW, and AAIW in the water mass inversion of section 3.1. In fact, the TS profiles and TS diagrams of stations 45 and 46 (not shown) indicate that the lense is probably a large intrusion of TW water into the SASW domain which has undergone some mixing with SASW and perhaps with the RLPW. The large intrusion is covered by a cap of RLPW. The low values in oxygen are as low as the $\mathrm{O}_{2}$ values observed in the TW core (between 4.75 and $\left.5.00 \mathrm{~mL} \mathrm{~L}^{-1}\right)$. This intrusion, unique by its spatial extent (of the order of $50 \mathrm{~km}$ ), is detached from the front; $T$, $\mathrm{S}$, and $\mathrm{O}_{2}$ conditions at station 47 are similar to those at station 44 . The intrusion is probably a coherent feature, such as a subsurface lense advected across the front.

3.2.2. Fine structure and associated mixing at the B-M front. We now quantify the vertical fine structure across the Brazil-Malvinas front and estimate the associated lateral heat and salt transfers across the front. The fine structures as observed in $T$ and $S$ at stations 40 and 47 , for example (Figure 7a), act to enhance the transfer of heat and salt by a variety of physical processes, such as double diffusion, diapycnal mixing, and cross-front lateral mixing. We evaluate the degree of lateral mixing using the statistical model 


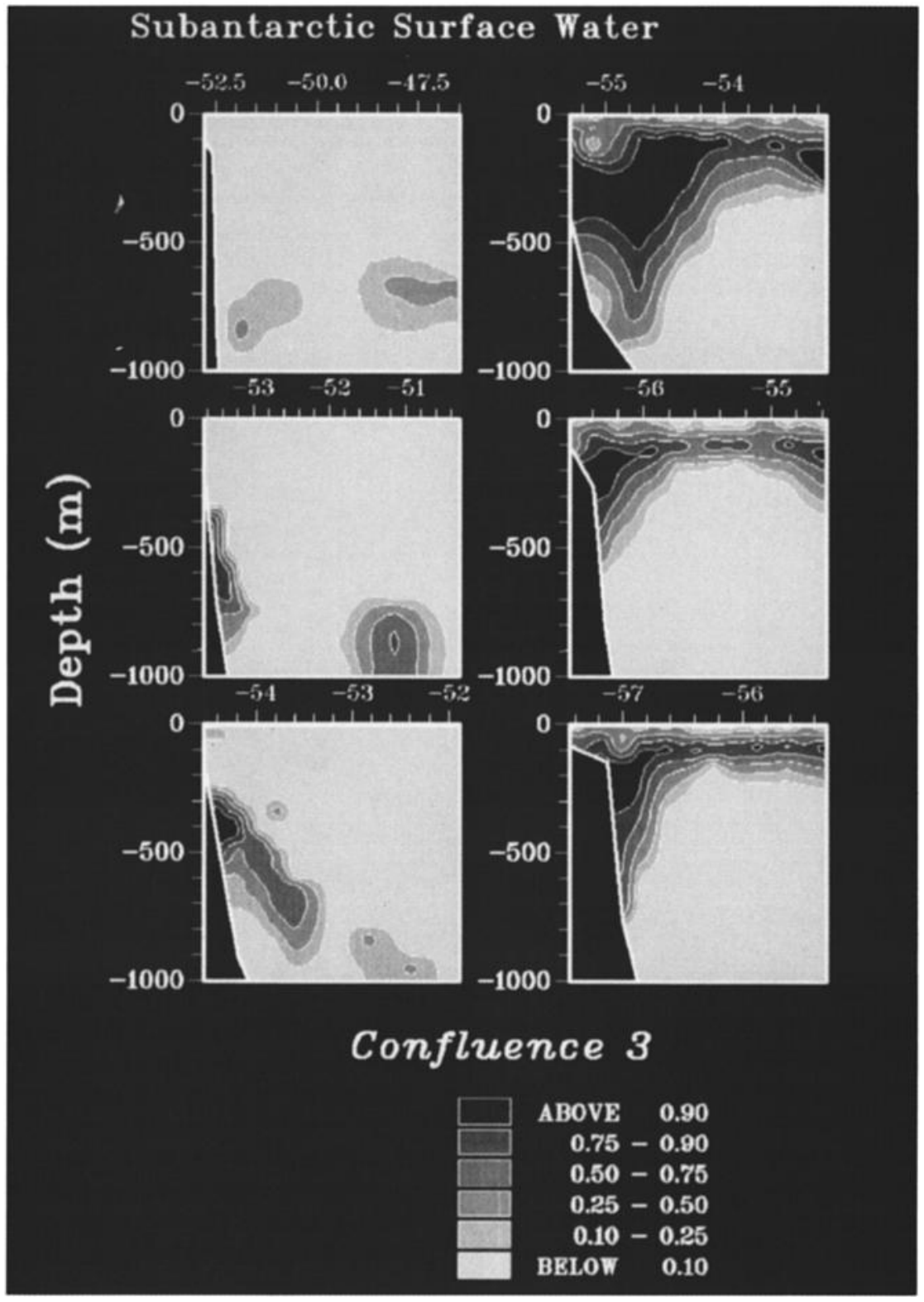

Figure 4b. Same as Figure 4a, except for Subantarctic Surface Water (SASW).

developed by Joyce [1977]. This model relates the lateral flux of property to the intensity of the fine structure. With the $x$ coordinate oriented along the front, the lateral flux of a property $\phi$ is given by:

$$
V \phi=-A_{\phi}[\overline{\partial \phi / \partial z}]^{2} / \overline{\partial \phi} / \partial y
$$

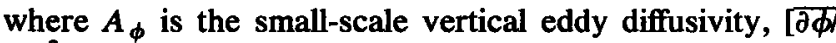
$\overline{\partial z}]^{2}$ is the variance of the vertical gradient, and $\partial \phi / \partial y$ is the large-scale cross-frontal horizontal gradient. The overbars indicate averaging of the gradient properties. Estimates for the vertical eddy diffusivity $A_{\phi}$ vary by 2 orders of magnitude [Garrett, 1979]. We use a value of $A_{\phi}=10^{-4} \mathrm{~m}^{2} \mathrm{~s}^{-1}$ following previous studies [Joyce, 1977; Joyce et al., 1978; Georgi, 1981; Piola and Georgi, 1982; Bianchi et al., 1993]. This way, we can compare our results on the basis of the property variance and horizontal gradients.
The vertical gradients of the detrended temperature and salinity were calculated on all stations at all depths to quantify the temperature and salinity fine structure. We concentrate here on the upper part of the water column (from 50 to $1000 \mathrm{~m}$, i.e., between the base of the mixed layer and the core of the AAIW) in order to estimate the heat and salt lateral fluxes between the TW and SASW/AAIW. Stations $\mathbf{4 7}$ and $\mathbf{4 0}$ exhibit the largest amplitude fine structure, with temperature gradients reaching $0.7^{\circ} \mathrm{C} \mathrm{m}^{-1}$ and salinity gradients $0.1 \mathrm{psu} \mathrm{m}^{-1}$ (Figure $7 \mathrm{~b}$ ). The spectra of the detrended temperature and salinity gradients have variable structures and slopes. At the stations closest to the front (stations 40 and 47 ) the vertical temperature gradient variances $[\partial \theta / \partial z]^{2}$ are $O\left[10^{-2}\right]\left({ }^{\circ} \mathrm{C} / \mathrm{m}\right)^{2}$ and the vertical salinity gradient variances $[\partial S / \partial z]^{2}$ are $O\left[10^{-3}\right](\mathrm{psu} / \mathrm{dbar})^{2}$ (Figures $7 \mathrm{c}$ and $7 \mathrm{~d}$ ). To estimate the large-scale cross-front 


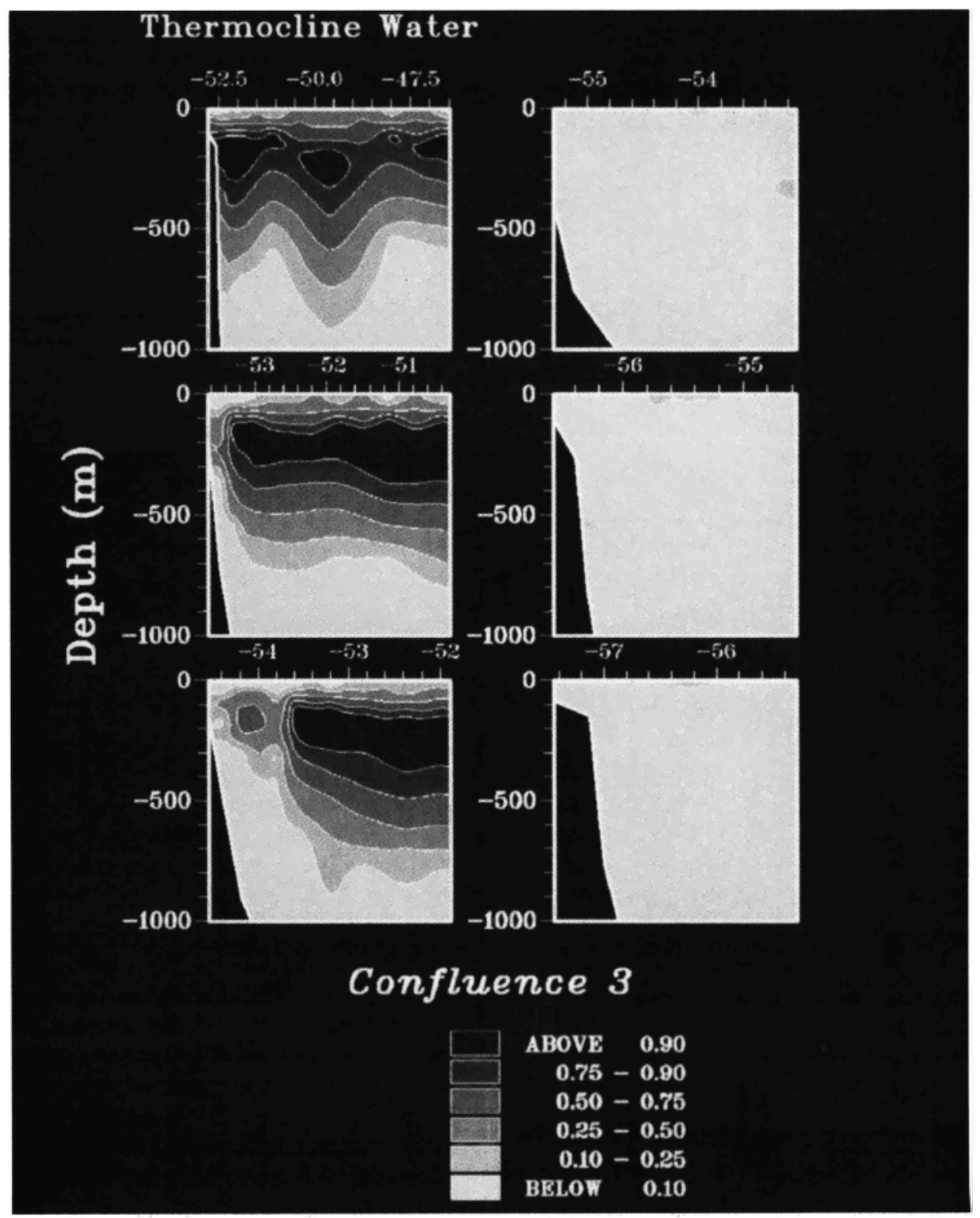

Figure 4c. Same as Figure 4a, except for Thermocline Water (TW).

property gradient $\partial \phi / \partial y$, we use the plots of the vertically averaged salinity and temperature over $50-500 \mathrm{~m}$ along sections $D$ and $C$ (already shown in Figure 6). The largescale cross-front temperature gradient $\partial \theta / \partial y$ is estimated as around $6^{\circ} \mathrm{C} / 100 \mathrm{~km}$ and the large-scale cross-front salinity gradient $\partial S / \partial y$ is of the order of $1.1 \mathrm{psu} / 100 \mathrm{~km}$.

As a result, we obtain values of $2.10^{-2 \circ} \mathrm{C} \mathrm{m}^{-1} \mathrm{~s}^{-1}$ and $1.10^{-3} \mathrm{psu} \mathrm{m}^{-1} \mathrm{~s}^{-1}$ for the lateral temperature and salinity fluxes across the front (following (1)). Dividing these fluxes by the horizontal temperature and salinity gradients yields a lateral heat diffusivity of $300 \mathrm{~m}^{2} \mathrm{~s}^{-1}$ and a lateral salinity diffusivity of $100 \mathrm{~m}^{2} \mathrm{~s}^{-1}$. These values are of the same order of magnitude as recent estimates made by Bianchi et al. [1993]. The values are extremely high, an order of magnitude greater than available estimates for other frontal regions. Even the estimates of the most energetic region in the main thermocline of the Gulf Stream front [Joyce, 1976] are significantly lower than those calculated in the B-M front.

This large lateral mixing will efficiently dissipate intrusive lenses. For example, the intrusive lense described in section 3.2.1 has mean temperature and salinity anomalies of $4^{\circ} \mathrm{C}$ and $0.5 \mathrm{psu}$, a thickness of $350 \mathrm{~m}$, and a lateral extent of about $50 \mathrm{~km}$. The small-scale mixing calculated above would dissipate such a heat and salt anomaly in about 3 to 4 months. Of course, the lense will also be affected by other processes, so this timescale is by no means an estimate of its lifespan.

\subsection{Mode Waters}

A "mode water" is a particular type of water mass characterized by its vertical homogeneity, which it acquires during wintertime vertical convection. The low vertical 


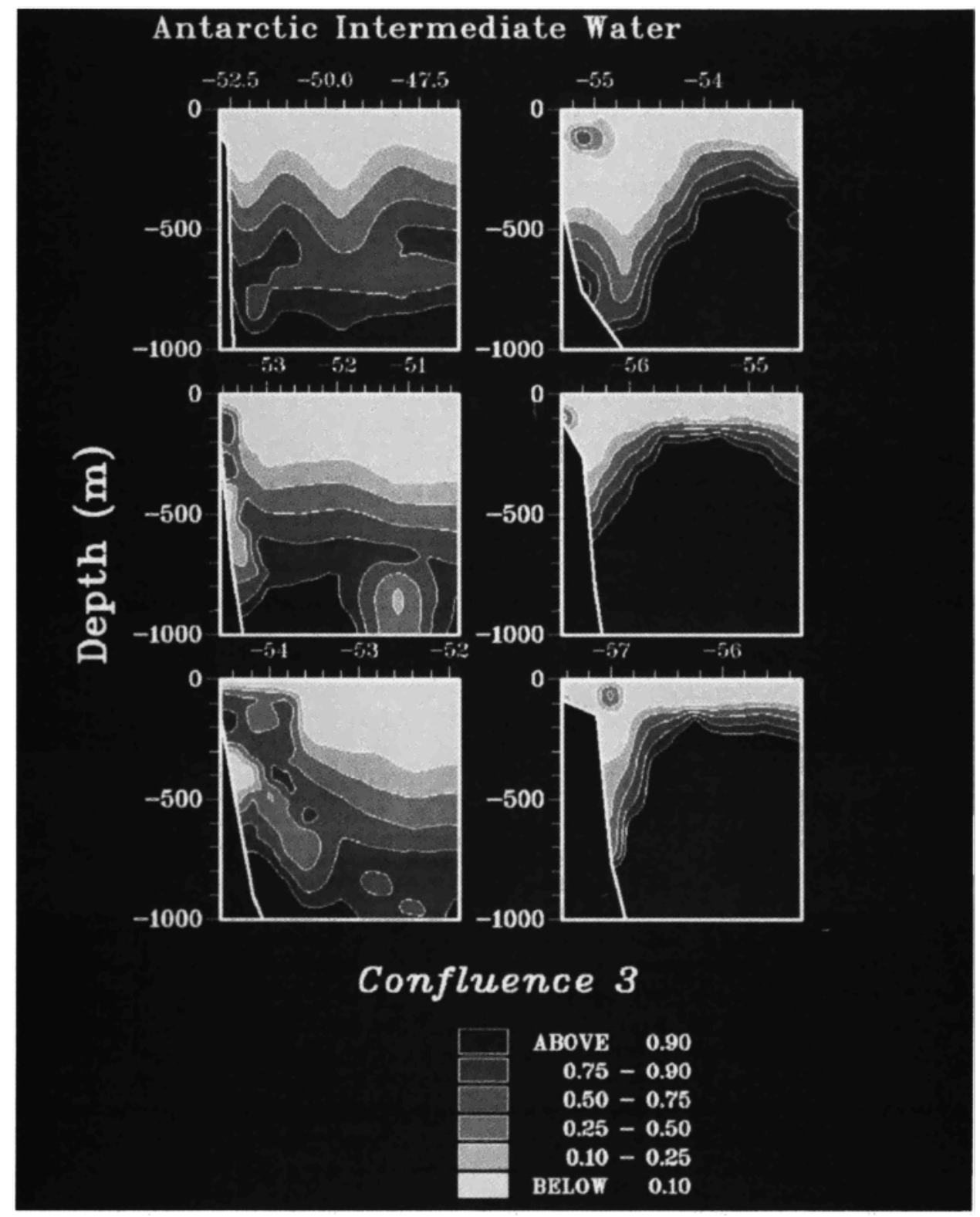

Figure 4d. Same as Figure 4a, except for Antarctic Intermediate Water (AAIW).

density gradient imparted to the water column by convection persists laterally as the general circulation carries the mode water away from the formation zone. This lateral persistence is a consequence of the conservation of potential vorticity.

Two major types of mode waters are encountered in the confluence region: Subtropical Mode Waters (STMW) and Subantarctic Mode Waters (SAMW) [McCartney, 1977, 1982; Greengrove, 1986]. They appear as minima on the potential vorticity sections (Figure 8). Potential vorticity was calculated following Millard et al. [1990].

3.3.1. STMW. The presence of Subtropical Mode Waters (STMW) during the Confluence 3 cruise is observed only on sections B and C at depths of about $200-400 \mathrm{~m}$ (Figure 8). These STMW are characterized by a potential vorticity of less than $10^{-10} \mathrm{~m}^{-1} \mathrm{~s}^{-1}$, a temperature of $14.5-16.0^{\circ} \mathrm{C}$, a range of 35.5 to $36 \mathrm{psu}$ in salinity, a local maximum in dissolved oxygen concentration of 4.85-5.05 $\mathrm{mL} \mathrm{L}^{-1}$, and a $\sigma_{t}$ density range of 26.3 to $26.5 \mathrm{~kg} \mathrm{~m}^{-3}$. These characteristics are the same on both sections. The STMW are formed in winter north of the subtropical front where the salty and warm TW in the Brazil Current overshoot encounters rough winter, subantarctic conditions with very dry and cold winds [Gordon, 1981]. Here we are observing remnant patches from wintertime convection. We do not have enough data to estimate the volume of STMW present, nor enough tracer data (like freons) to estimate its age. Such data might indicate whether the STMW was formed the previous winter and how regularly it is produced.

3.3.2. SAMW. Patches of potential vorticity minima associated with Subantarctic Mode Waters (SAMW) are found on every section (Figure 8). On sections $F$ and $E$ those patches are characterized by a potential vorticity less than 


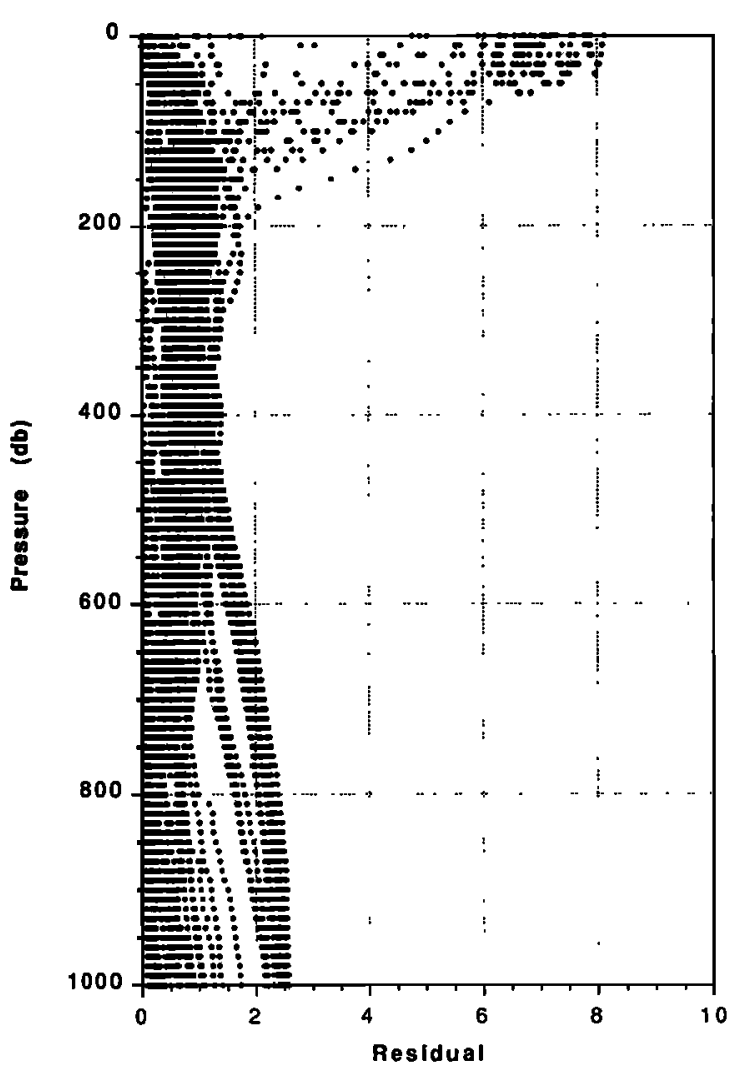

Figure 4e. Residuals versus depth for all Confluence 3 stations.

$0.5 \times 10^{-10} \mathrm{~m}^{-1} \mathrm{~s}^{-1}$, an halostad at $34.165 \mathrm{psu}$, a local maximum in oxygen with values higher than $6.5 \mathrm{~mL} \mathrm{~L}^{-1}$, a temperature between 4.1 and $4.9^{\circ} \mathrm{C}$, and values of $\sigma_{t}$ ranging from 27.02 to $27.10 \mathrm{~kg} \mathrm{~m}^{-3}$. Those patches are squeezed along the continental slope at depths of 200 to $400 \mathrm{~m}$.

On section D, patches of SAMW are observed not only close to the continental slope, but also in the eastern part of the section. However, these patches of SAMW correspond to different types of mode waters. The SAMW on the western part of section D has characteristics very similar to those of the SAMW on sections F and $E$ except for the salinity values which do not correspond to the "perfect" halostad of sections $E$ and F, rather to a slight halocline from 34.136 to $34.174 \mathrm{psu}$. This patch of SAMW is found at a depth of 340 to $750 \mathrm{~m}$ and extends over $1^{\circ}$ of longitude. The patch of SAMW on the eastern side of section D is characterized by a minimum of potential vorticity $(q<0.5 \times$ $10^{-10} \mathrm{~m}^{-1} \mathrm{~s}^{-1}$ ) and a local maximum of oxygen of $5.63 \mathrm{~mL}$ $\mathrm{L}^{-1}$. Its salinity ranges from 34.25 to $34.31 \mathrm{psu}$, its temperaiure from 4.43 to $5.36^{\circ} \mathrm{C}$, and its $\sigma_{t}$ from 27.09 to $27.17 \mathrm{~kg}$ $\mathrm{m}^{-3}$. It is observed at depths of 380 to $600 \mathrm{~m}$. This eastern patch is poorer in oxygen (by $1 \mathrm{~mL} \mathrm{~L}^{-1}$ ), saltier (by 0.15 psu), and warmer (by about $0.4^{\circ} \mathrm{C}$ ) than the western patch. It is found on $\sigma_{t}$ surfaces that are deeper by $0.1 \mathrm{~kg} \mathrm{~m}^{-3}$.

On section $C$ the SAMW are clearly observed on all stations from station 44 to station 51. Again, we observe two different types of mode waters. The first one, with characteristics similar to those of the SAMW observed on sections $\mathrm{E}$ and $\mathrm{F}$, is present on stations 44 to 48 . Its core deepens offshore from $500 \mathrm{~m}$ at station 44 to $800 \mathrm{~m}$ at station 48 . The second type of SAMW (with $q$ less than $0.5 \times 10^{-10} \mathrm{~m}^{-1}$ $s^{-1}$ ) is observed on the eastern part of the section from stations 49 to 51 , as a 300 -m-thick layer in the depth range 800 to $1100 \mathrm{~m}$. Again, the eastern patch is saltier ( $34.24 \mathrm{psu}$ ), poorer in oxygen $\left(5.65 \mathrm{~mL} \mathrm{~L}^{-1}\right)$, warmer $\left(4.2\right.$ to $\left.5.2^{\circ} \mathrm{C}\right)$, and found on deeper $\sigma_{t}$ surfaces $\left(27.05\right.$ to $27.15 \mathrm{~kg} \mathrm{~m}^{-3}$ ).

On section $B$ there is no longer SAMW over the continental slope. It is found offshore (stations 35,34 , and 33) with $q$ less than $0.5 \times 10^{-10} \mathrm{~m}^{-1} \mathrm{~s}^{-1}$ at a depth range of 750 to 1100 $\mathrm{m}$. Its oxygen is as high as $6.03 \mathrm{~mL} \mathrm{~L}^{-1}$ (local $\mathrm{O}_{2}$ maximum), its salinity lower than 34.19 psu, with a minimum at 34.170 psu. The values in $\sigma_{t}$ vary from 27.0 to $27.12 \mathrm{~kg} \mathrm{~m}^{-3}$ and in temperature from 4.0 to $5.2^{\circ} \mathrm{C}$. Those values are observed at station 34. At stations 33 and 35 the values are eroded, with $5.6 \mathrm{~mL} \mathrm{~L}^{-1}$ for the $\mathrm{O}_{2}$ maximum and $34.24 \mathrm{psu}$ for salinity. On section A, SAMW is found ( $q$ less than $0.55 \times 10^{-10}$ $\mathrm{m}^{-1} \mathrm{~s}^{-1}$ ) between $\sigma_{t}$ values of 27.05 and $27.20 \mathrm{~kg} \mathrm{~m}^{-3}$ (that is, within a depth range of $600-1000 \mathrm{~m}$ ). It is characterized by a salinity minimum at $34.2 \mathrm{psu}$, a temperature ranging from 4.0 to $5.3^{\circ} \mathrm{C}$, and a local maximum in $\mathrm{O}_{2}$ with values higher then $5.50 \mathrm{~mL} \mathrm{~L} \mathrm{~L}^{-1}$. SAMW is found at each station from station 28 to station 32, although we see some erosion of SAMW at station 29.

The origin of these SAMW in the South Atlantic has been a subject of controversy since 1935 [e.g., Wüst, 1935; Martineau, 1953; McCartney 1977, 1982; Georgi, 1978; Molinelli, 1981]. Summarizing all the observations and evaluating the different hypotheses, Piola and Gordon [1989] conclude that SAMW must have an Antarctic component. They also report two water types of low salinity entering the southwestern Atlantic through the Drake Passage. The less dense of the water types, named type A (typical characteristics of $4.8^{\circ} \mathrm{C}, \mathrm{S}>34.2 \mathrm{psu}, \sigma_{t}=27.10 \mathrm{~kg} \mathrm{~m}^{-3}$ ), the coldest variety of SAMW, is formed by deep convection in the southeast Pacific. It is of subantarctic origin and is freshened and cooled in the Argentine Basin by winter air-sea interaction near Burdwood Bank. The denser water mass, type $B\left(3.8^{\circ} \mathrm{C}, \mathrm{S}<34.2, \sigma_{t}=27.15-27.20 \mathrm{~kg} \mathrm{~m}^{-3}\right)$ outcrops south of the Antarctic Convergence (AAC) and is probably influenced by Antarctic waters upstream of the Drake Passage. It includes colder Antarctic water and is richer in oxygen. Piola and Gordon [1989] show that the type A water cannot progress north of $43^{\circ} \mathrm{S}$ as the isopycnals $\sigma_{t}=$ $27.10 \mathrm{~kg} \mathrm{~m}^{-3}$ turn east and south adjacent to deeper isopycnals associated with the southward extension of the Brazil Current. The region covered by Confluence 3 CTD stations is located north of $42^{\circ} \mathrm{S}$, and as such, we did not find any type $A$ mode water.

Undoubtedly, the SAMW patches on sections $F, E$, and on the western part of sections $C$ and $D$ have $T, S, O_{2}$, and $\sigma_{t}$, values that are close to the characteristics of type B mode waters. On sections $E$ and F this type B SAMW is squeezed along the continental slope, trapped by the doming of the isopycnals on the western edge of the Malvinas Current. On sections $C$ and $D$ it progressively detaches from the continental slope. This type B SAMW, carried by the Malvinas Current, has its characteristics eroded as it progresses northward. On section C the type B SAMW is mixed at the front; it gets saltier, warmer, and poorer in oxygen and deepens. At the frontal area in the patches of low potential vorticity, mixing processes are enhanced. Diapycnal processes may be responsible for the deepening of isopycnal surfaces of the SAMW. The SAMW on section B is deeper and poorer in oxygen $\left(5.85 \mathrm{~mL} \mathrm{~L}^{-1}\right)$ and can be 


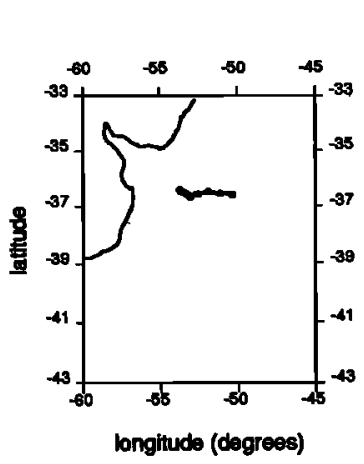

$\theta$
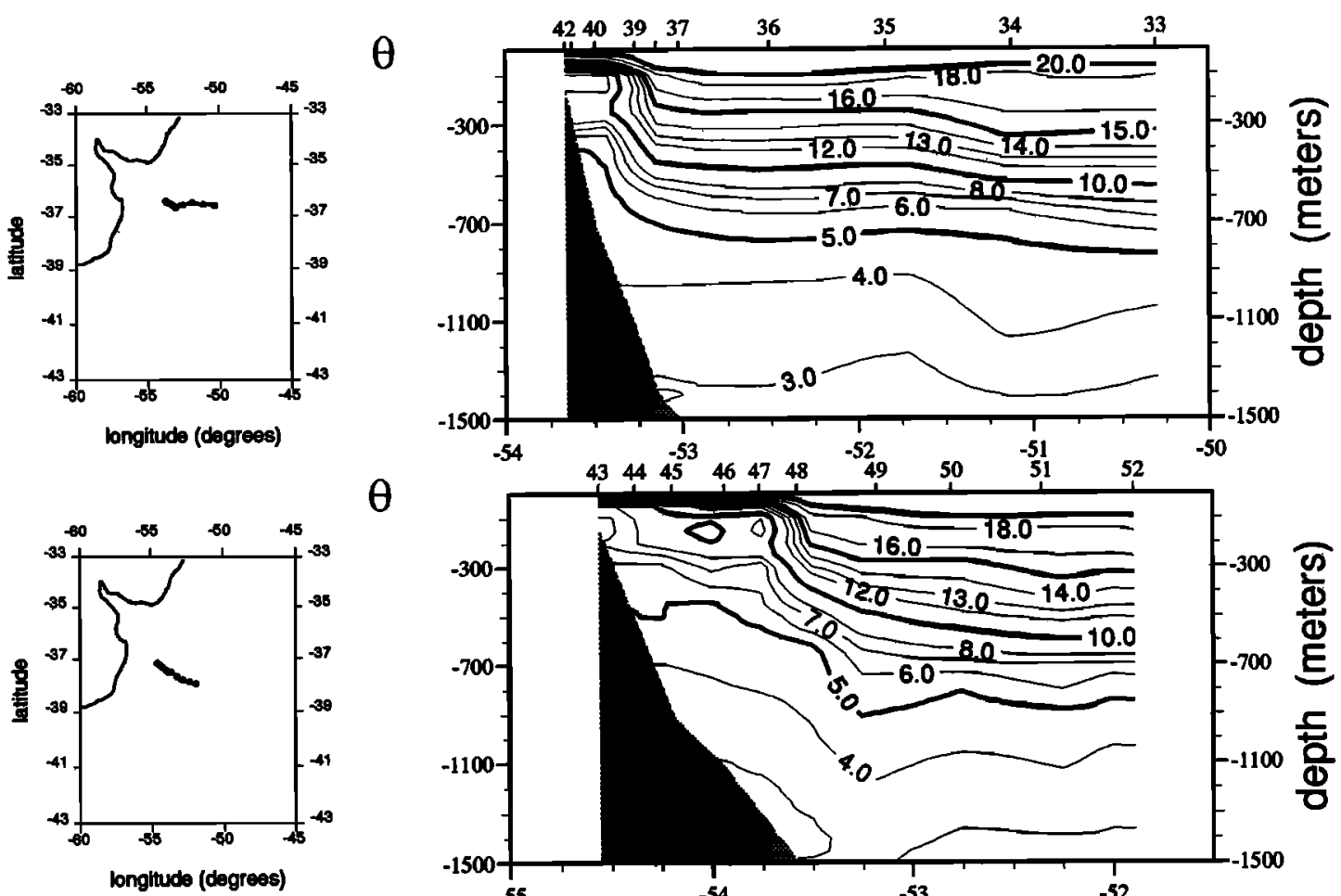

$\theta$

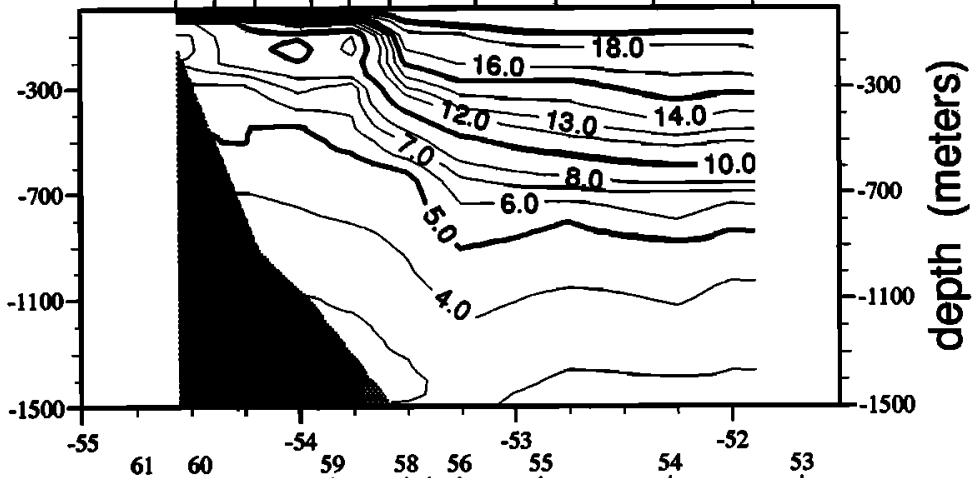

$\theta$
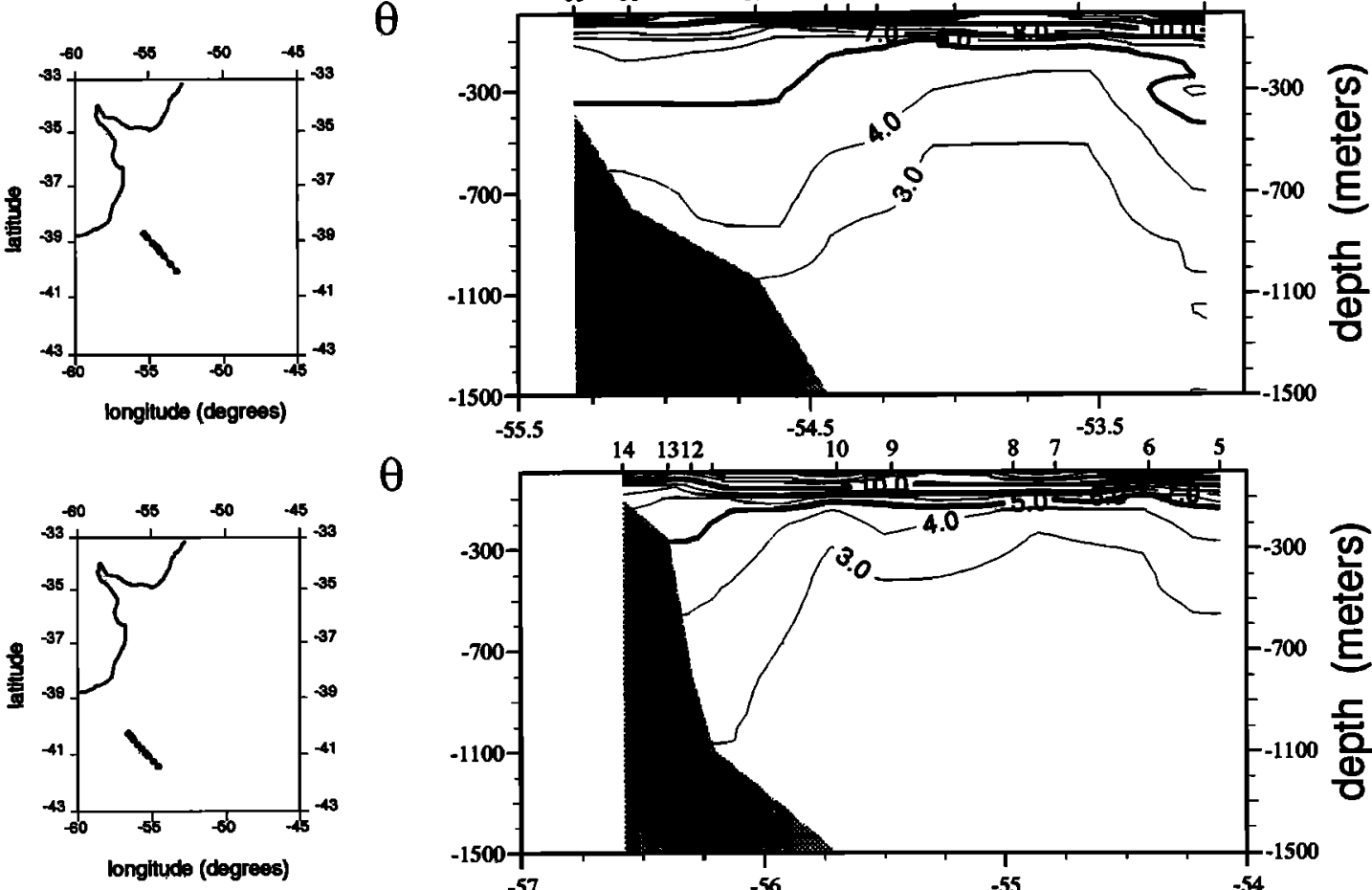

$\theta$

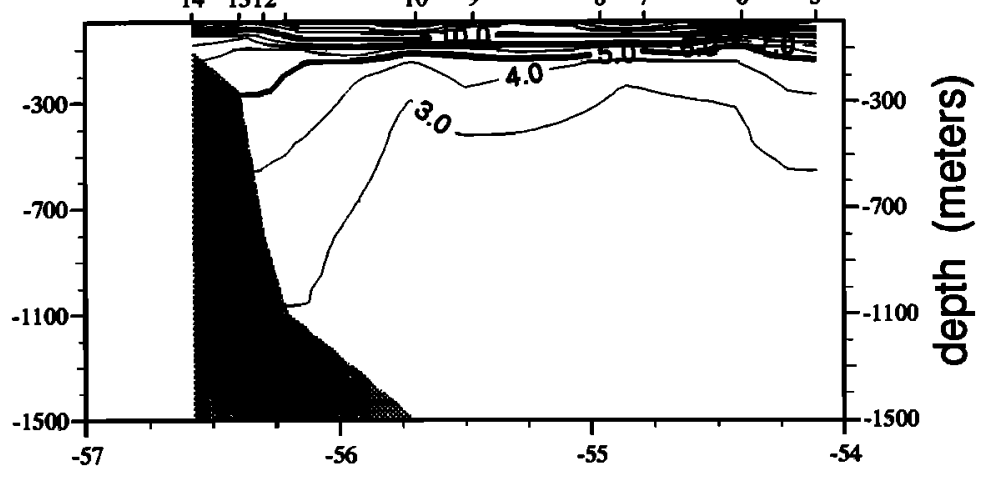

longitude (degrees)

Figure 5a. Potential temperature on sections B, C, D, and E (0-1500 m). 


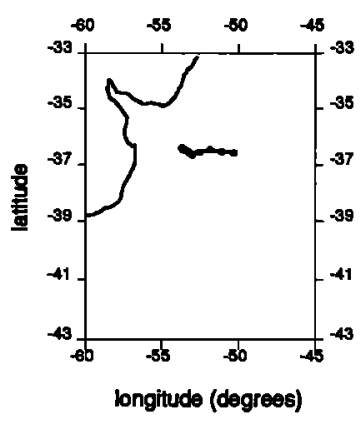

S
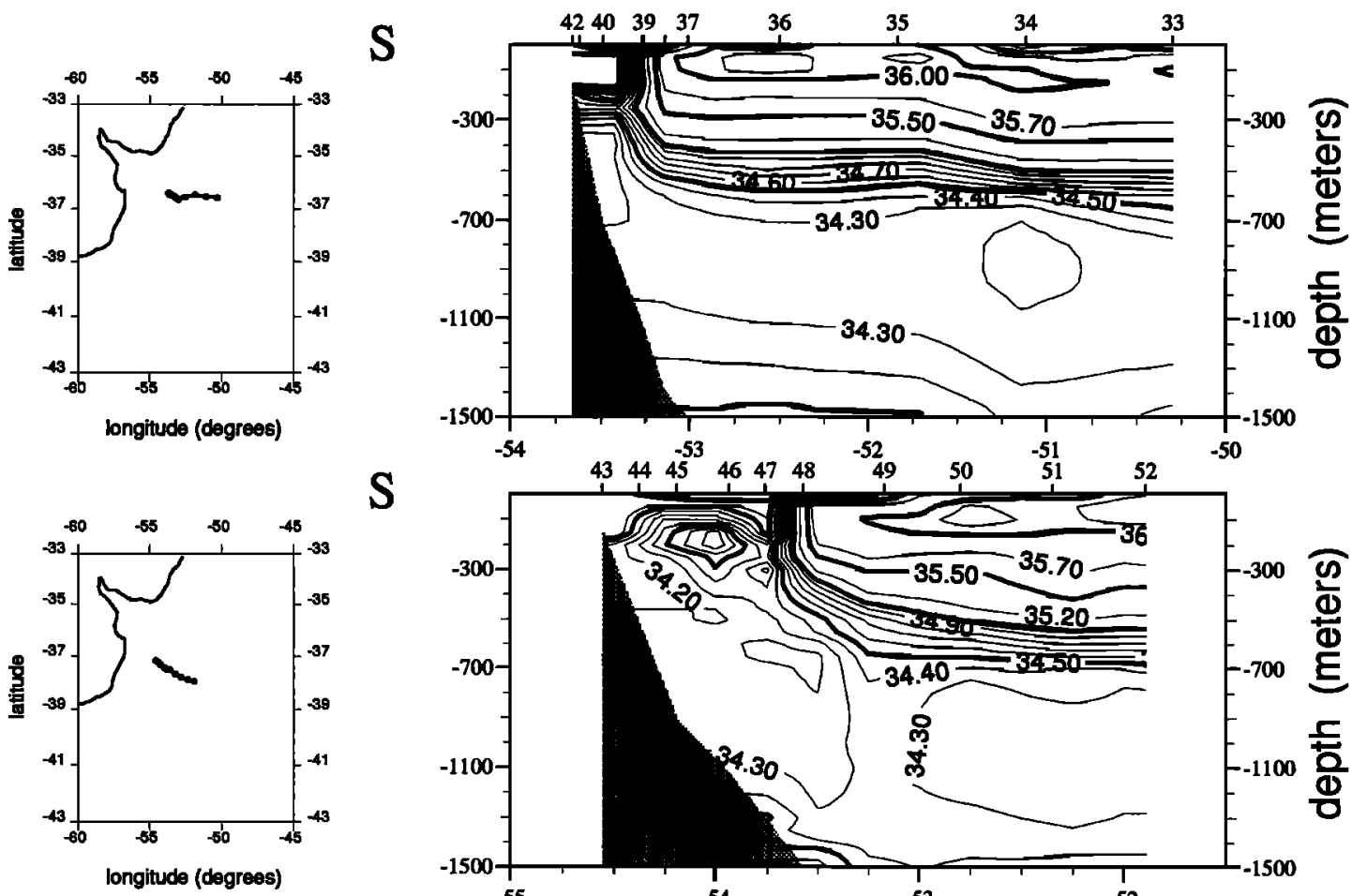

S
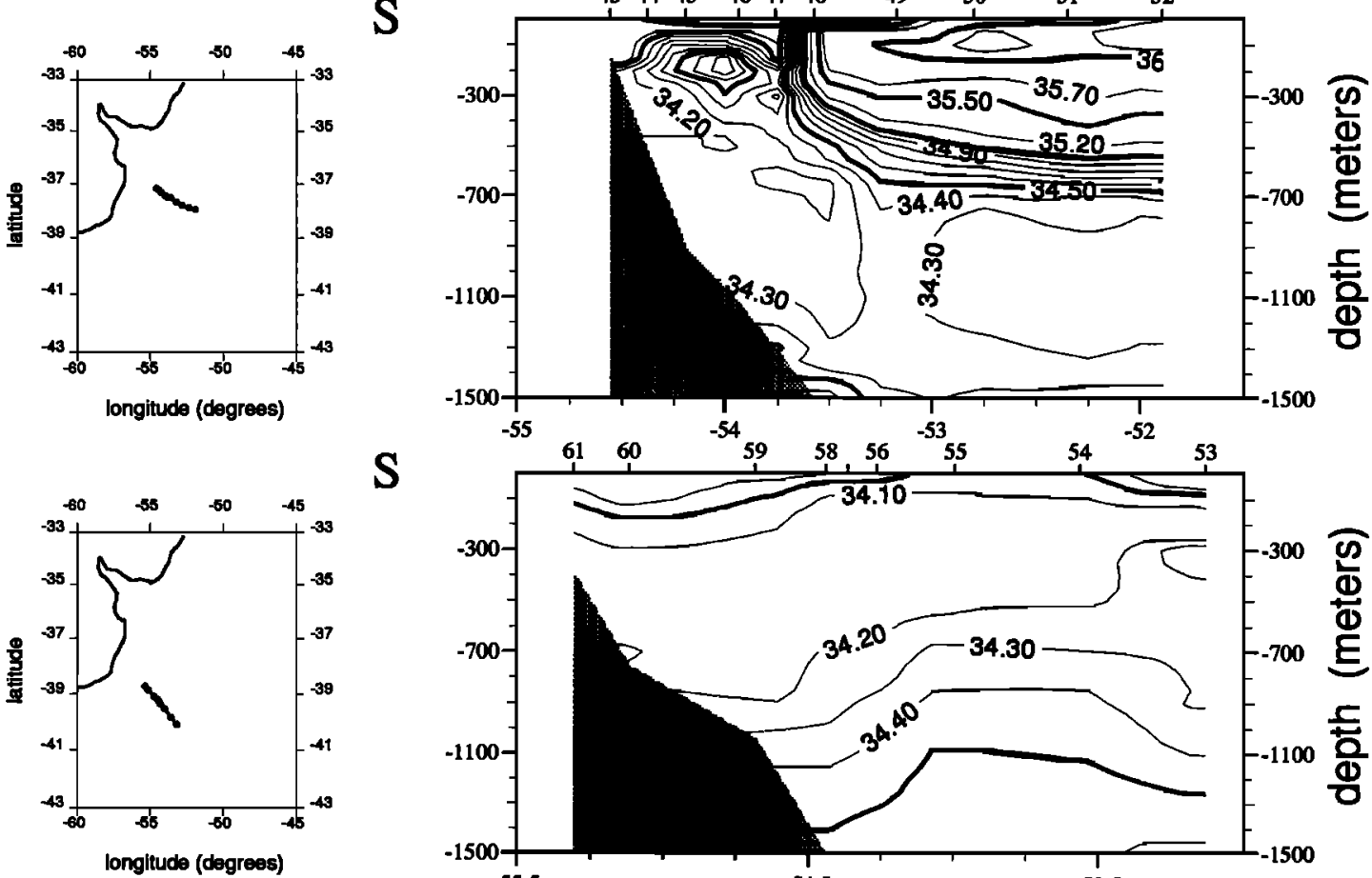

S
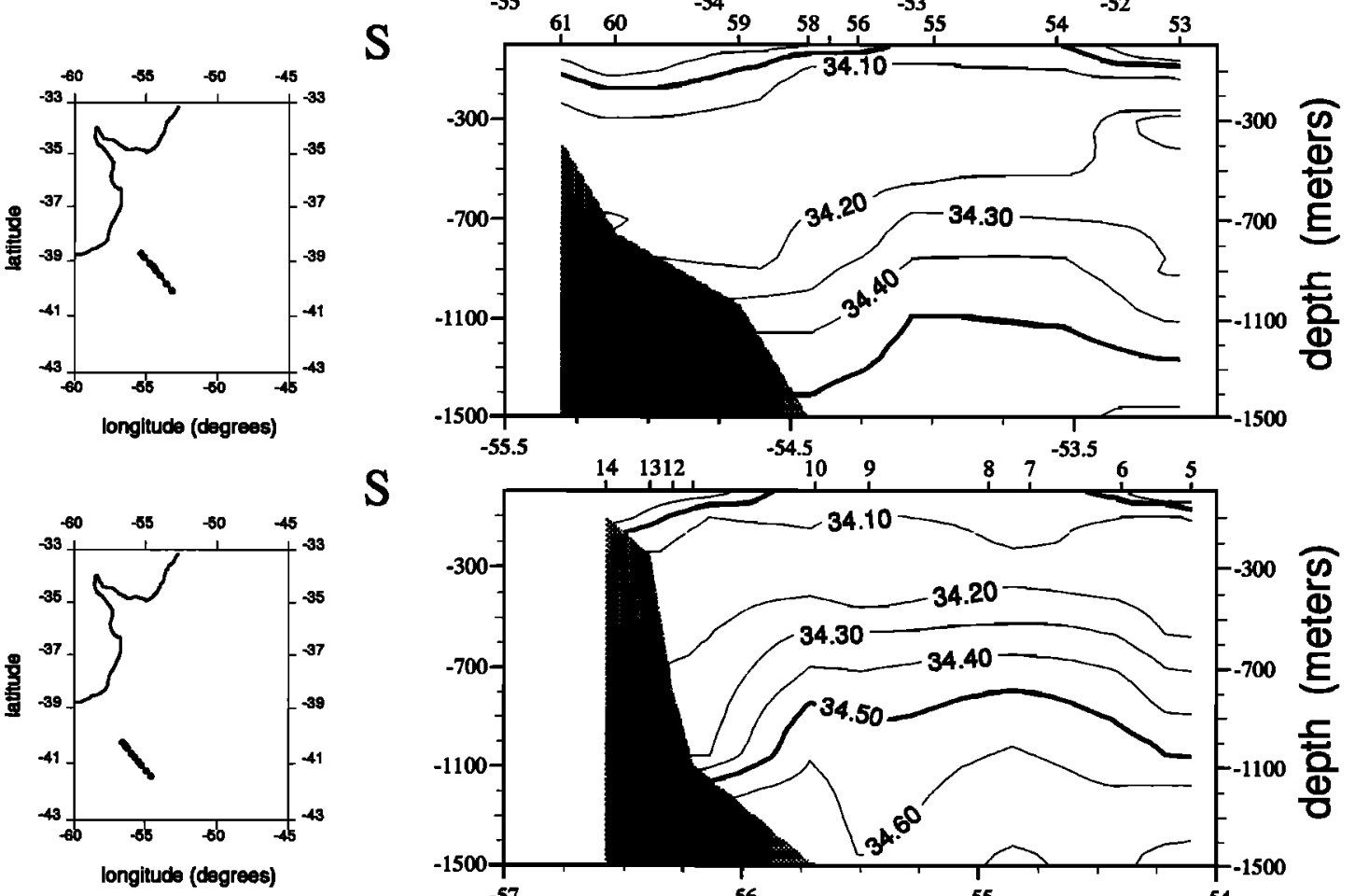

S

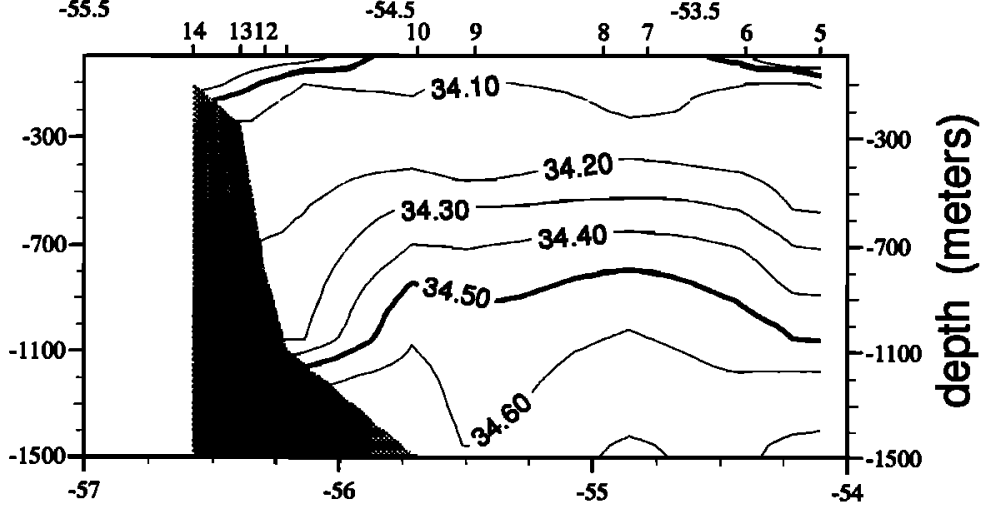

longitude (degrees)

Figure 5b. Salinity (practical salinity units) on sections B, C, D, and E (0-1500 m). 

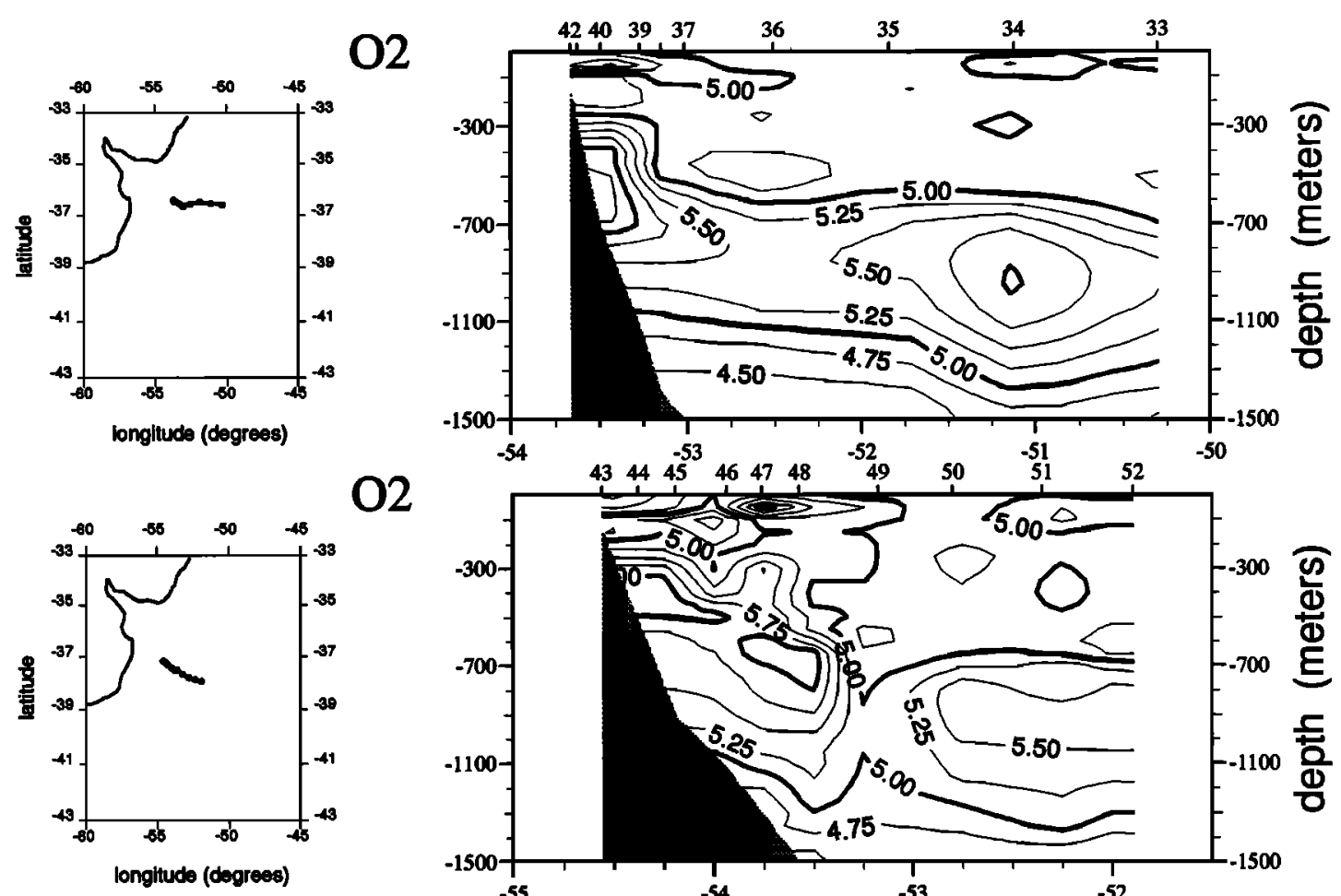

$\mathrm{O} 2$
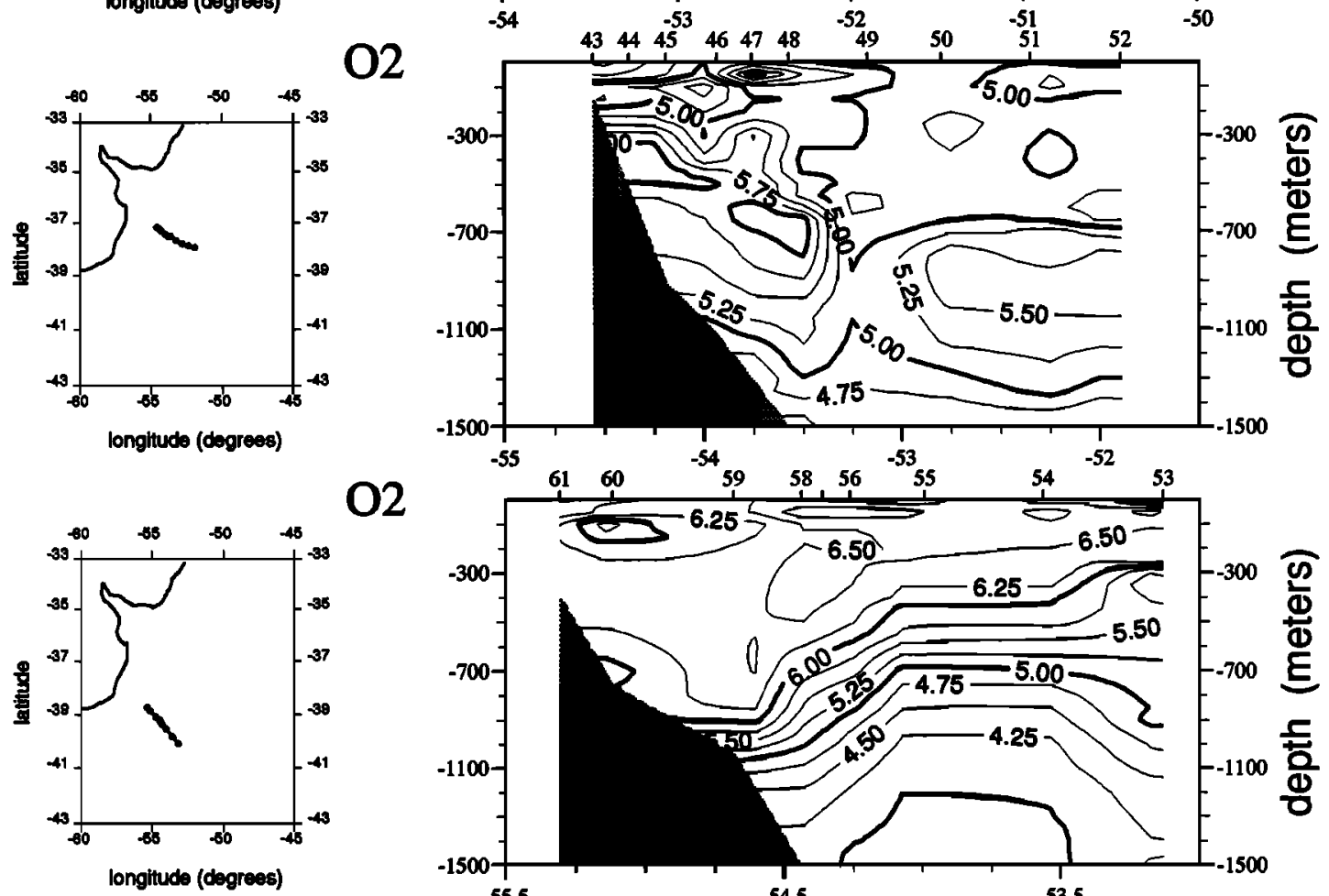

$\mathrm{O} 2$

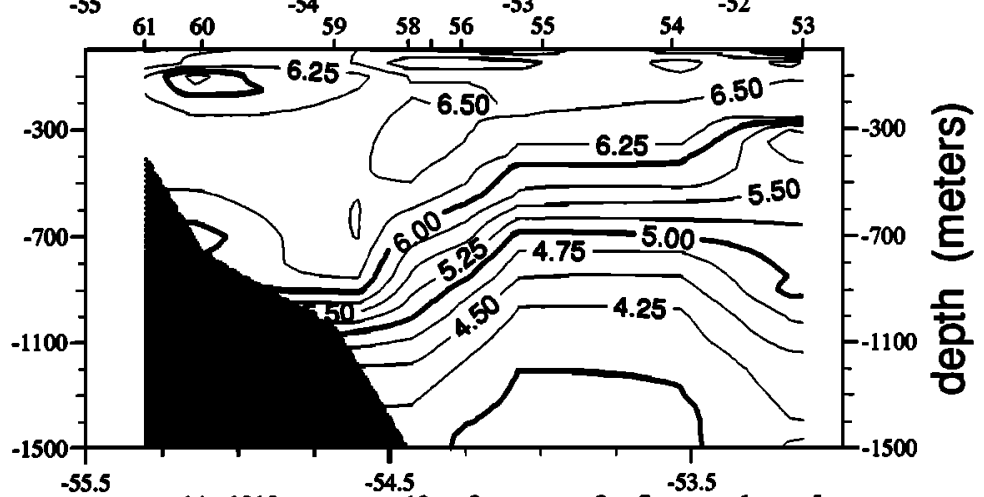

$\mathrm{O} 2$
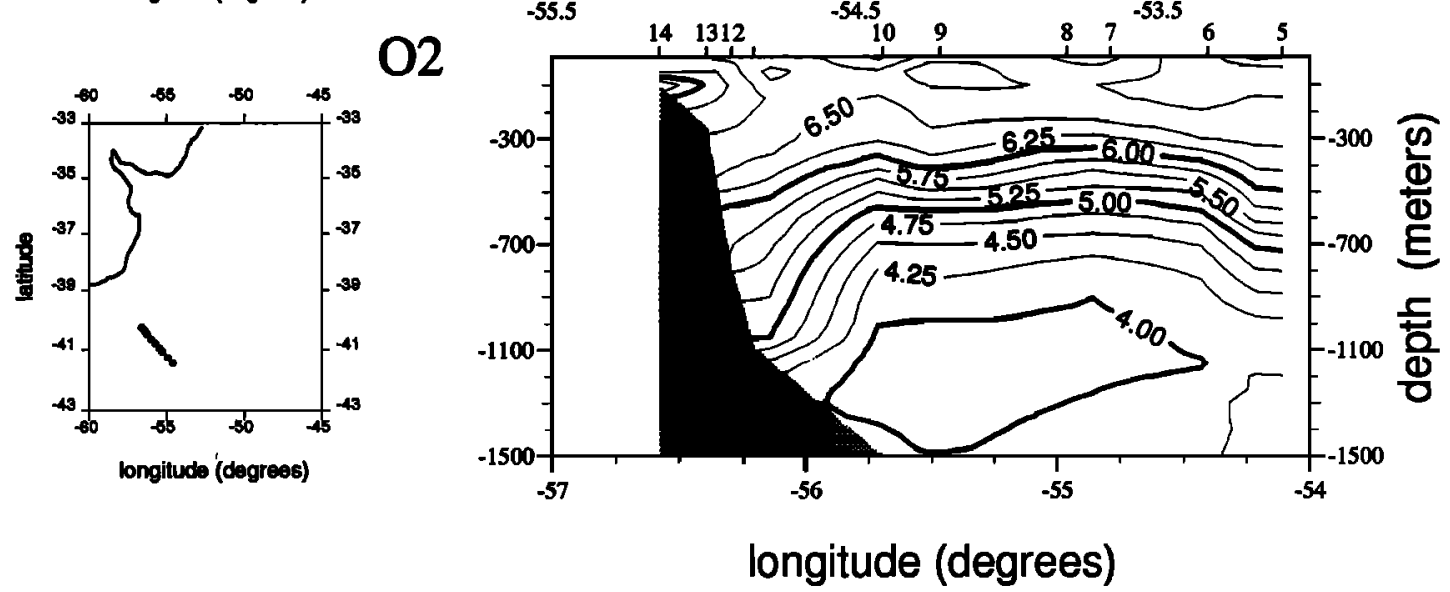

Figure 5c. Oxygen (in milliliters per liter) on sections B, C, D, and E (0-1500 m). 

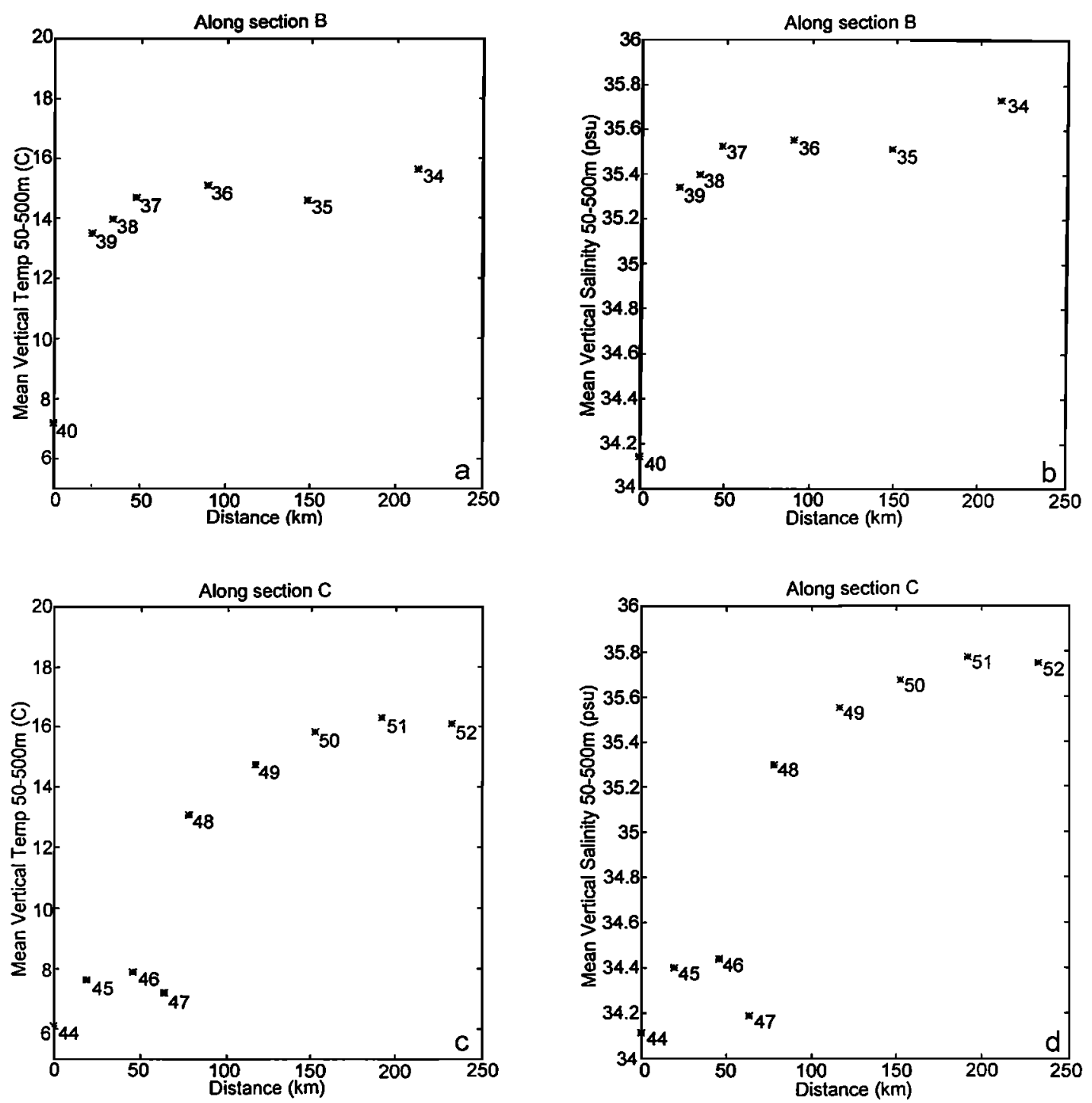

Figure 6. Vertically integrated (a) temperature and (b) salinity (from 50 to $500 \mathrm{~m}$ ) as a function of distance along section $B$ and (c) temperature and (d) salinity along section $\mathrm{C}$.

considered a type B mode water, having undergone some mixing at the front. The remnants of mode water on section $A$ are very eroded and mixed.

SAMW is also found on the eastern part of sections $C$ and D. The pattern of observed SAMW and T, S, $\mathrm{O}_{2}$, and $\sigma_{t}$ characteristics is consistent with a recirculation hypothesis. SAMW found on the eastern part of sections $D$ and $C$ could be SAMW recirculating to the south: SAMW appears richer in oxygen on section $C$ than on section $D$. On section $A$, patches of SAMW are very eroded and mixed, and this is why lower $\mathrm{O}_{2}$ values are found. The change of propagation to the south would occur near section B. SAMW of type B would progress northward along the continental slope until a latitude corresponding to section $\mathrm{C}$, getting slightly saltier, poorer in oxygen, warmer, and denser. Between sections $C$ and $\mathrm{D}$ it detaches from the coast and continues northward, crossing the frontal region (TW-AAIW front) where it is strongly altered. On section $B$, which is close to its northernmost extension, it is considerably altered (particularly salinity and oxygen). It is then entrained southward with the Malvinas return flow and the Brazil Current extension. As it progresses southward, it continues to mix with TW of the Brazil Current extension and loses oxygen, gains salinity, and gets warmer. We do not get the complete story of this type B SAMW, since sections $E$ and $F$ do not extend sufficiently to the east.

AAIW does not appear entirely as a mode water with a homogeneous minimum in potential vorticity. Although the potential vorticity is quite low throughout the AAIW body in the confluence region, the synoptic view of Confluence 3 data allows us to observe the (recirculation of the minima and their erosion. The formation of the AAIW body is complex in this region, and some time averaging is included in the notion of water masses.

\section{Deep Levels}

In this section we focus on the deep layers, the NADW and CDW, in the approximate depth range $1000-3500 \mathrm{~m}$. The NADW forms the deep branch of the Brazil Current and flows in close proximity to the continental slope [Reid et al., 1977]. The CDW, the deep counterpart of the Malvinas 


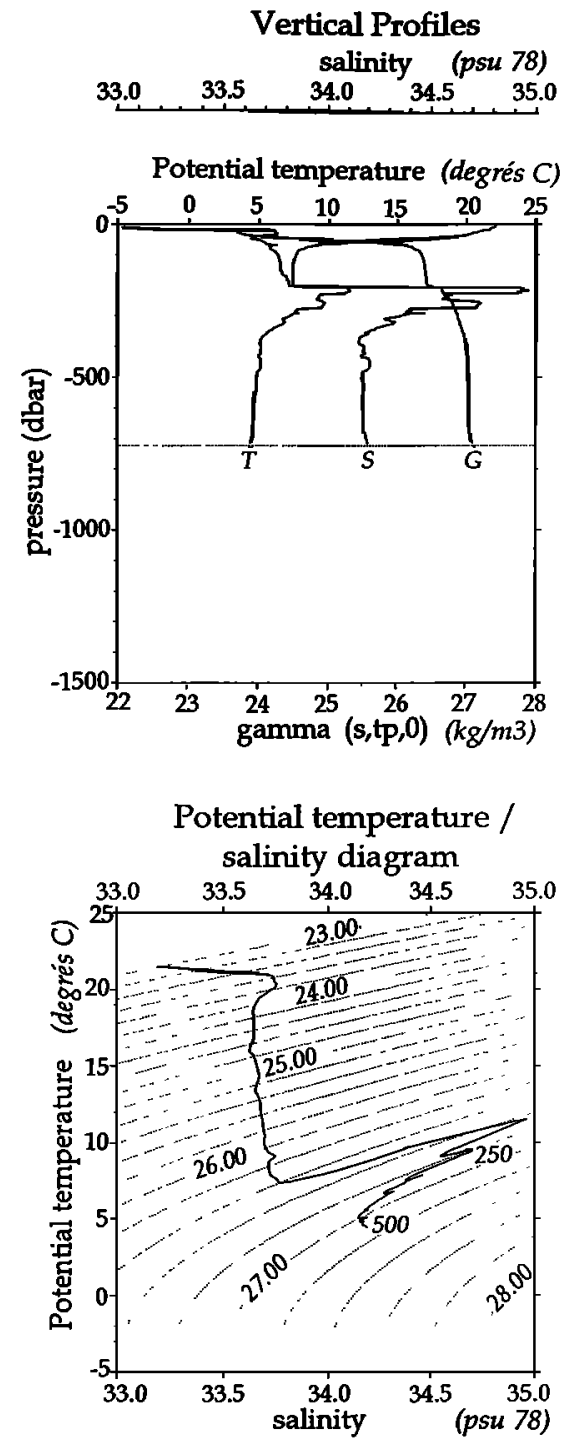

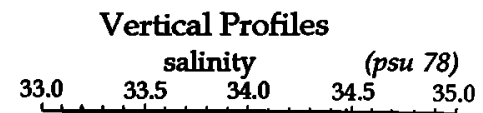

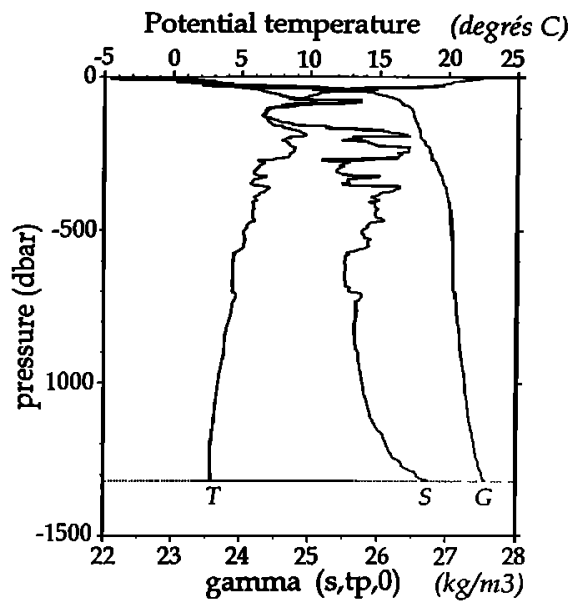

Potential temperature / salinity diagram

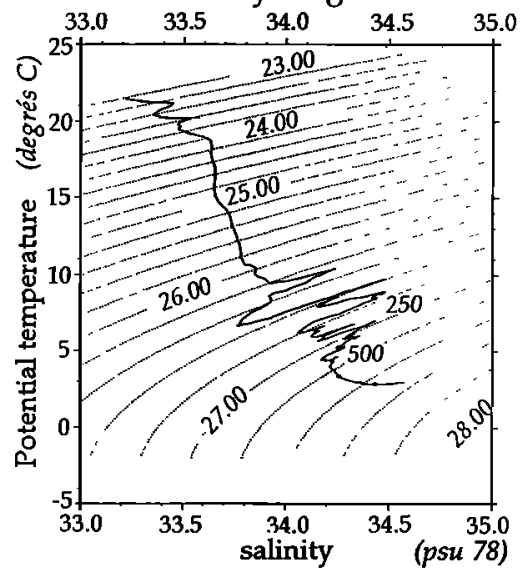

Figure 7a. Temperature and salinity profiles and potential temperature/salinity diagrams at stations (left) 40 and (right) 47 . Isopycnals are referenced to a pressure of 0 dbar.

Current, flows northward along the western margin of the South Atlantic [Reid et al., 1977]. Around $40^{\circ} \mathrm{S}$, south of the Brazil-Malvinas Confluence, the NADW and CDW converge to form a complex system [Georgi, 1981]. Farther north, the NADW separates the CDW into two branches, the UCDW and the LCDW [Reid et al., 1977]. In the Confluence area, Maamaatuaiahutapu et al. [1992, 1994] describe the situation in the NADW/CDW system during a winter and a spring cruise. On the basis of the mixing proportion analysis, they find that the NADW, and consequently the CDW, cores undergo considerable variation in location. We report here the latitudinal evolution of the NADW/CDW system during the summer of 1990 and then examine the mixing at the NADW/CDW confluence.

\subsection{Latitudinal Evolution of the Deep Water Structure}

The Confluence 3 CTD stations located over the continental slope provide a good description of the NADW/CDW system near the western boundary. The NADW is associated with higher salinity, temperature, and oxygen values. At the water mass scale the observations made by previous authors can be viewed on the Confluence 3 data set. On Figure 2 we see that on the southern section $F$ a homogeneous layer (1500 $\mathrm{m}$ to bottom) west of station 20 is to be associated with the CDW. This component of CDW wedged between the slope and the NADW evolves in a vigorous mixing process as the CDW progresses northward. The complexity of the NADW/CDW confluence was first described by Georgi [1981].

Figures $9 a$ and $9 b$ report the $\Theta / S$ and $S / O_{2}$ diagrams for deep waters (depths greater than $1000 \mathrm{~m}$ ) along the six Confluence 3 sections. The $\Theta$ is referenced to $1000 \mathrm{~m}$. Because deep waters are found at shallower depth in the south, the $\Theta / S$ and $S / O_{2}$ diagrams on sections $A$ and $B$ include some AAIW, while the "1000-m limit" is only slightly above the core of the UCDW on sections $E$ and F. The Weddell Sea Deep Water (WSDW) is very sharply defined on all diagrams. The WSDW is observed on the three easternmost stations of each section.

On sections $A, B$, and $C$ the core of NADW is clearly developed, with its maximum in $\mathrm{O}_{2}, \Theta$, and $\mathrm{S}\left(\mathrm{O}_{2}>5.4 \mathrm{~mL}\right.$ 

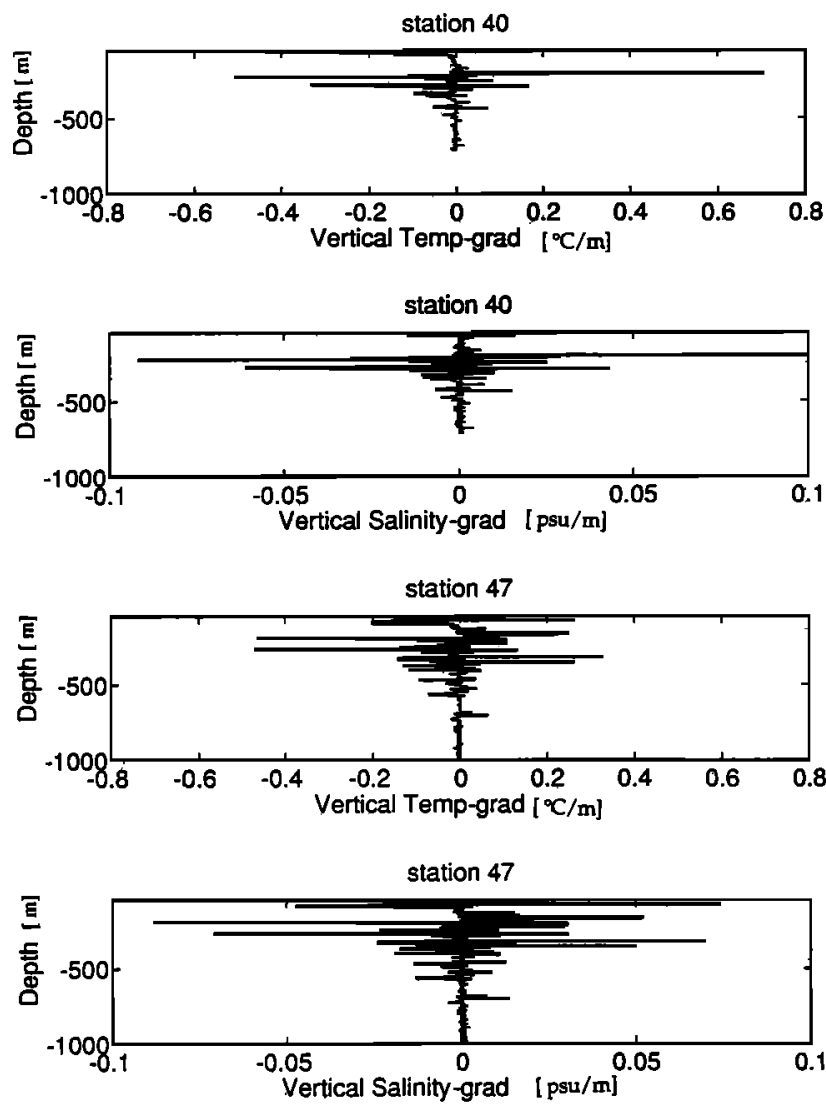

Figure 7b. Temperature and salinity gradients at stations 40 and 47.

$\mathrm{L}^{-1}, \Theta>3^{\circ} \mathrm{C}$, and $\left.\mathrm{S}>34.9 \mathrm{psu}\right)$. The NADW leaves the coast between sections $C$ and $D$. On sections $D, E$, and $F$, NADW is only seen in small patches to the east of the $4000-\mathrm{m}$ isobath (Figure 2). On the $\Theta / \mathrm{S}$ and $\mathrm{S} / \mathrm{O}_{2}$ diagrams of sections $D, E$, and F, NADW characteristics are eroded and fine structures are abundant.

On the three northern sections (A, B, C) the UCDWNADW-LCDW system on the $\Theta / S$ diagrams is well defined, whereas it is not on the southern sections (Figure 9a). The

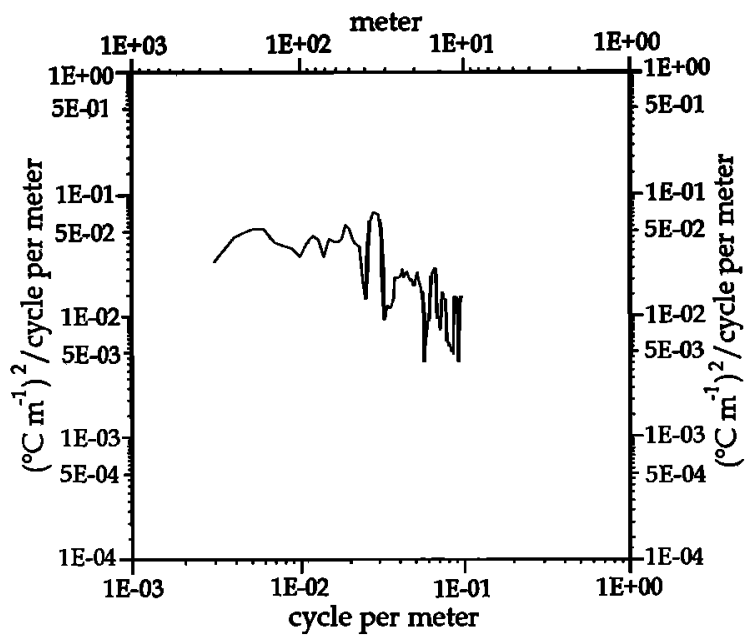

Figure 7c. Spectrum of detrended temperature at station 47.

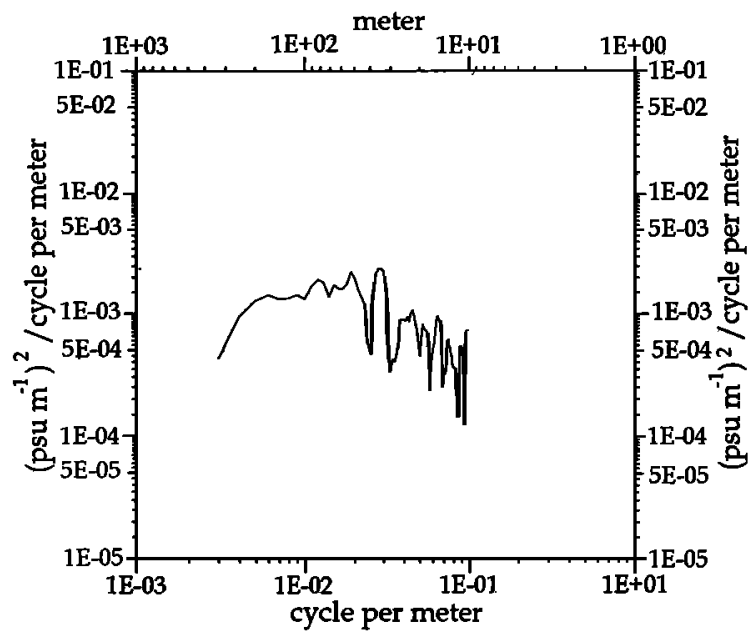

Figure 7d. Spectrum of detrended salinity at station 47 .

lowest curve on the $\Theta / S$ diagrams of the three southern sections (D, E, F) corresponds to the CDW on the western part of each section. To the west of each section there is no NADW. However, the CDW is not pure and homogeneous, rather, it shows influence of a weak UCDW-NADW-LCDW structure (Figure 9a). This UCDW-NADW-LCDW structure is even clearer on the $\mathrm{O}_{2} / \mathrm{S}$ diagrams (Figure $9 \mathrm{~b}$ ).

The UCDW has a low $\mathrm{O}_{2}$ content (less than $4 \mathrm{~mL} \mathrm{~L}^{-1}$ ) on section $\mathrm{F}$ (Figure 9b). It gets richer in $\mathrm{O}_{2}$ as it progresses north and mixes with NADW. On sections $C$ and $D$ the $\mathrm{UCDW} \mathrm{O} \mathrm{O}_{2}$ concentration is of $4.3 \mathrm{~mL} \mathrm{~L}^{-1}$. On section $A$ the UCDW exhibits a wide range of oxygen from 4 to $4.5 \mathrm{~mL}$ $\mathrm{L}^{-1}$. The lowest values correspond to the most offshore stations (e.g., station 32) where UCDW has characteristics similar to those of section $F$. The higher values in oxygen correspond to the westernmost station reaching that depth (i.e., station 28) where mixing with NADW has been the strongest (Figure 9b). In the same manner, on the $\Theta / S$ diagrams (Figure 9a), the lowest temperature value at the level of UCDW corresponds to the easternmost station (station 32) and to temperature very close to those observed on section $\mathrm{F}$ for UCDW. Therefore only the water along the slope appears affected by the mixing. The LCDW remains rather unaffected in its $\Theta, S$, and $\mathrm{O}_{2}$ characteristics.

\subsection{Mixing at the NADW-CDW Convergence}

The mixing of the remnant patches of NADW with the CDW creates important fine structures in sections $D$ and $E$. Figure 10a shows detailed profiles of $T, S$, and $\mathrm{O}_{2}$ for station 6 of section $E$. Interleaving (inversions) in $T$ and $S$ are associated with inversions in $\mathrm{O}_{2}$.

We can estimate the lateral mixing due to these intrusions at the NADW/CDW front in $T$ and $S$ again using the statistical model of Joyce [1977]. The large-scale gradient in $\mathbf{T}$ (respectively, in $S$ ) is estimated from the lateral variations of the vertically integrated $T$ (respectively, S) between 1500 and $2500 \mathrm{~m}$ along sections $D$ and $E$ (Figure 10a). The NADW/CDW front appears to be located between stations 55 and 54 on section $D$ and between stations 6 and 5 on section $\mathrm{E}$. The large-scale gradient on temperature is larger on section $\mathrm{E}\left(1.2^{\circ} \mathrm{C} / 100 \mathrm{~km}\right)$ than on section $\mathrm{D}\left(0.8^{\circ} \mathrm{C} / 100\right.$ $\mathrm{km})$, whereas the salinity gradient is weaker in section $\mathrm{E}$ $(0.12 \mathrm{psu} / 100 \mathrm{~km})$ than on section $\mathrm{D}(0.18 \mathrm{psu} / 100 \mathrm{~km})$ 

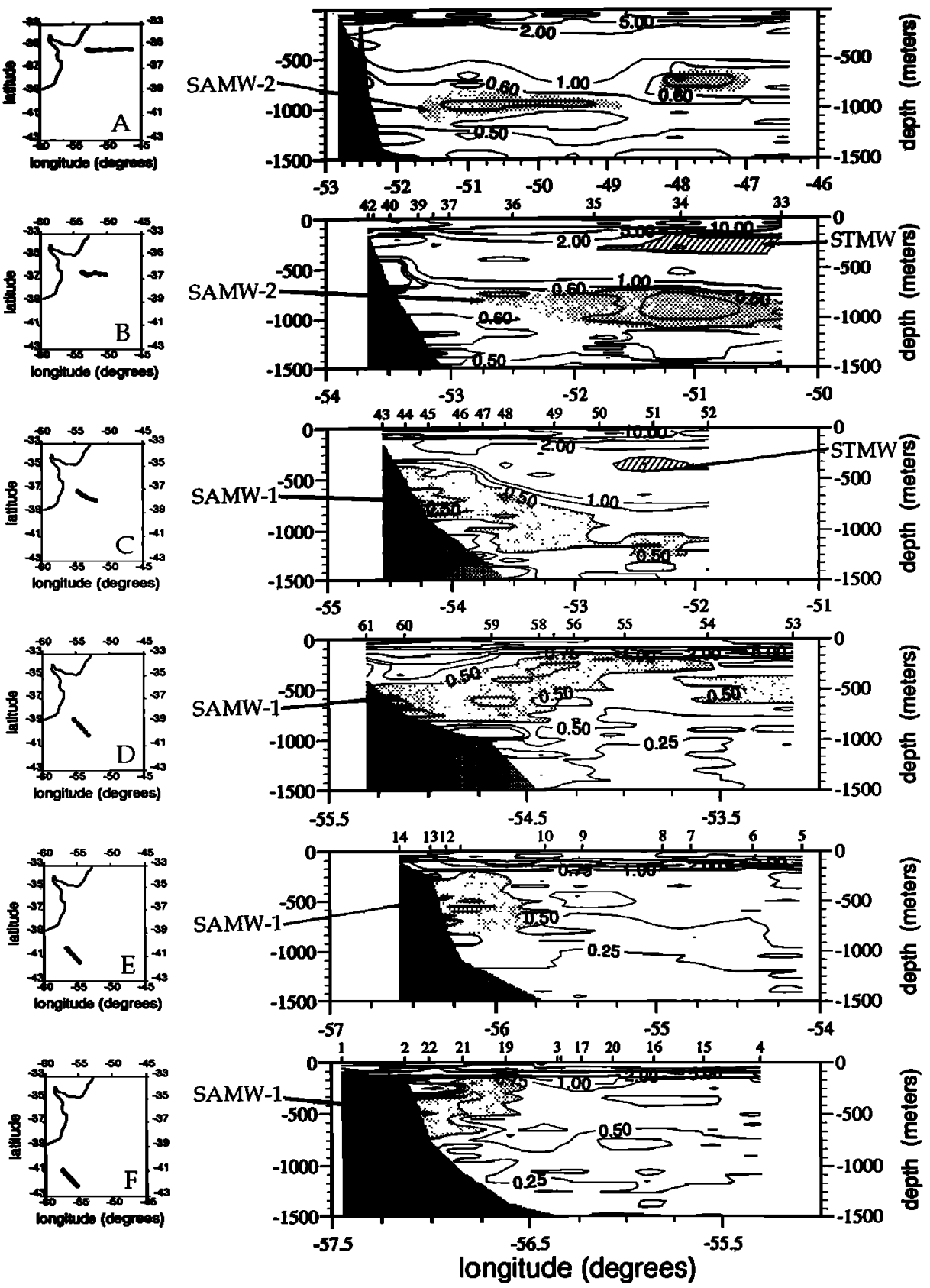

Figure 8. Potential vorticity (PV) along all the Confluence 3 vertical sections. Units are $10^{-10} \mathrm{~m}^{-1} \mathrm{~s}^{-1}$. Isocontours are at every $1.0 \times 10^{-10} \mathrm{~m}^{-1} \mathrm{~s}^{-1}$ above the $1.010^{-10} \mathrm{~m}^{-1} \mathrm{~s}^{-1}$ value, they are every $0.1 \times$ $10^{-10} \mathrm{~m}^{-1} \mathrm{~s}^{-1}$ below. Minima of PV are dotted and labeled according to the mode water they correspond to: Subtropical Mode Waters (STMW) (patches on sections B and C), Subantarctic Mode Waters (SAMW)-1 (relatively new SAMW found along the continental slope on sections F, E, D, and C), and SAMW-2 (altered or recirculated SAMW on sections A, B, and the eastern part of sections C and D).

(Figure 10b). However, fine structures in temperature and salinity have larger amplitudes on section $D$ than on section E. On section $D$, fine structures create vertical temperature and salinity gradients that can reach over $0.1^{\circ} \mathrm{C} \mathrm{m}^{-1}$ and over $0.02 \mathrm{psu} \mathrm{m}^{-1}$ (Figure 10c).

Power spectra of temperature and salinity vertical gradients provide estimates of their variances (Figure 10d). They were calculated between the depth of the 36.9 and $37.1 \sigma_{2}$ isopycnals. An ensemble average spectrum was then formed for each station. The temperature variance for stations 6 or
55 is of $O\left(5 \times 10^{-4}\right)\left({ }^{\circ} \mathrm{C} / \mathrm{m}\right)^{2}$ and salinity variance is of $O$ $\left(3 \times 10^{-5}\right)(\mathrm{psu} / \mathrm{m})^{2}$ (Figure 10c).

Using (1) and a vertical eddy diffusivity of $10^{-4} \mathrm{~m}^{2} \mathrm{~s}^{-1}$, we obtain values of $5 \times 10^{-3}{ }^{\circ} \mathrm{C} \mathrm{m}^{-1} \mathrm{~s}^{-1}$ for the lateral temperature flux and $2 \times 10^{-3} \mathrm{psu} \mathrm{m}^{-1} \mathrm{~s}^{-1}$ for the lateral salinity flux. Dividing those fluxes by the horizontal temperature and salinity gradient yields a horizontal heat diffusivity of $500 \mathrm{~m}^{2} \mathrm{~s}^{-1}\left(5 \times 10^{6} \mathrm{~cm}^{2} \mathrm{~s}^{-1}\right)$ and a horizontal salt diffusivity of $100 \mathrm{~m}^{2} \mathrm{~s}^{-1}$.

Georgi [1978] has estimated the lateral temperature flux in 

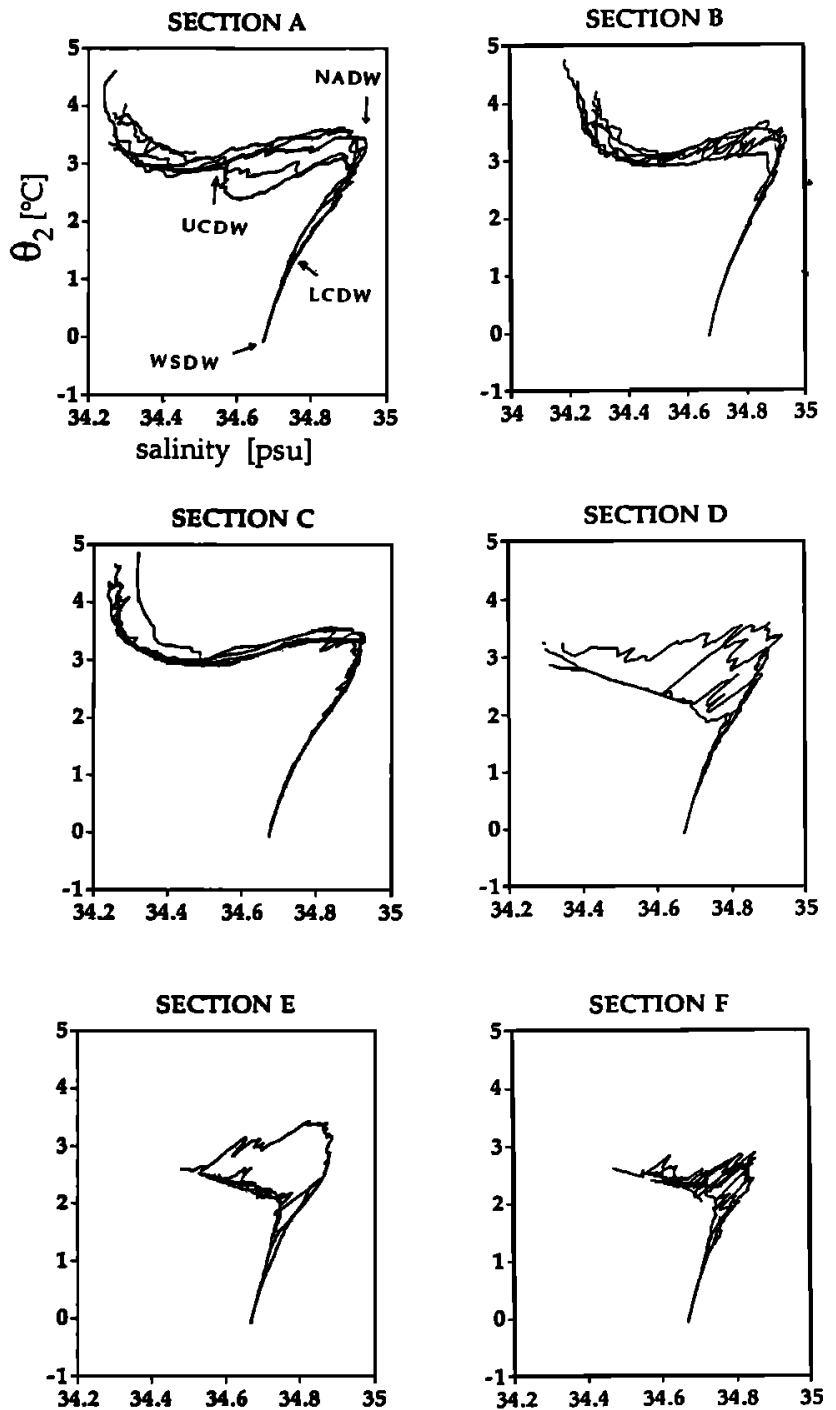

Figure 9a. Deep level $\theta / \mathrm{S}$ diagrams on all Confluence 3 sections ( $\theta$ referred to $2000 \mathrm{~m}$ ).

the deep waters in the southwestern Atlantic. The lateral temperature flux obtained here is larger than Georgi's estimate by an order of magnitude. This is because the largescale gradients used are of the same amplitude (about $1^{\circ} \mathrm{C} / 100 \mathrm{~km}$ ) in the two studies, while the fine structure is more intense during our survey. Bianchi et al. [1993] have also estimated temperature and salinity flux in the southwest Atlantic. Their estimates are also one order of magnitude smaller than ours, essentially because they compute their estimate at the latitude of the B-M Confluence and not at the latitude of the CDW/NADW Confluence which occurs somewhat south of it. Therefore they find smaller-amplitude large-scale gradients (smaller than ours and Georgi's) and less intense fine structure.

\section{Summary and Conclusions}

The Confluence 3 cruise during February 1990 provides the first hydrographic survey of the Brazil-Malvinas Confluence region during an austral summer. It is also the first survey in the region with such a refined spatial resolution over the slope-open ocean transition area.
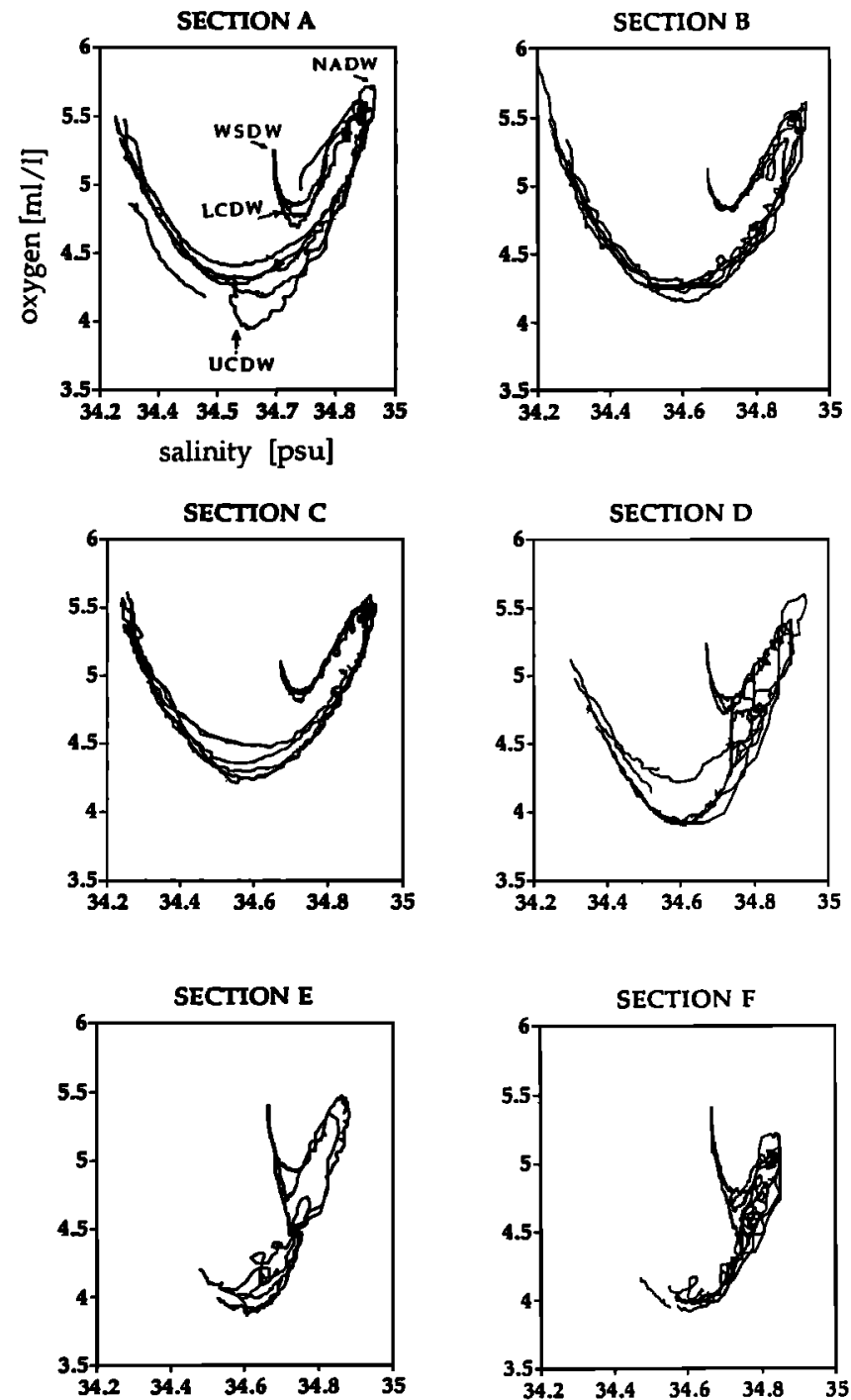

Figure 9b. Deep level S/O2 diagrams on all Confluence 3 sections.

The Malvinas Water is squeezed along the continental slope on the two southernmost sections and is observed to split into the following two branches on section $D$ : the eastern branch returning southward and the western one continuing northward to sink below the TW. The northward flowing, narrow vein of Malvinas Water squeezed along the slope is observed as far north as $36.3^{\circ} \mathrm{S}$, somewhat farther north than expected.

Two sections cross the Brazil-Malvinas front. The front has a north-south orientation near the continental slope and an east-west orientation offshore. The front is very steep in both temperature and salinity; the vertically integrated temperature and salinity over the layer $50-500 \mathrm{~m}$ vary by over $6.5^{\circ} \mathrm{C}$ and $1.2 \mathrm{psu}$ in less than $14 \mathrm{~km}$. A large intrusive lense of cross section $50 \mathrm{~km}$ and thickness $350 \mathrm{~m}$, with mean temperature and salinity anomalies of $4.0^{\circ} \mathrm{C}$ and $0.5 \mathrm{psu}$, is observed inshore of the Brazil-Malvinas front. Vertical fine structure in $\mathrm{T}, \mathrm{S}$, and $\mathrm{O}_{2}$ is encountered at almost every station. The fine structure intensity increases as the front is approached. At stations close to the front, vertical temperature and salinity gradients of $0.7^{\circ} \mathrm{C} \mathrm{m}^{-1}$ and $0.1 \mathrm{psu} \mathrm{m} \mathrm{m}^{-1}$ are observed. Using Joyce's [1976, 1977] model, we obtain $2 \times$ 

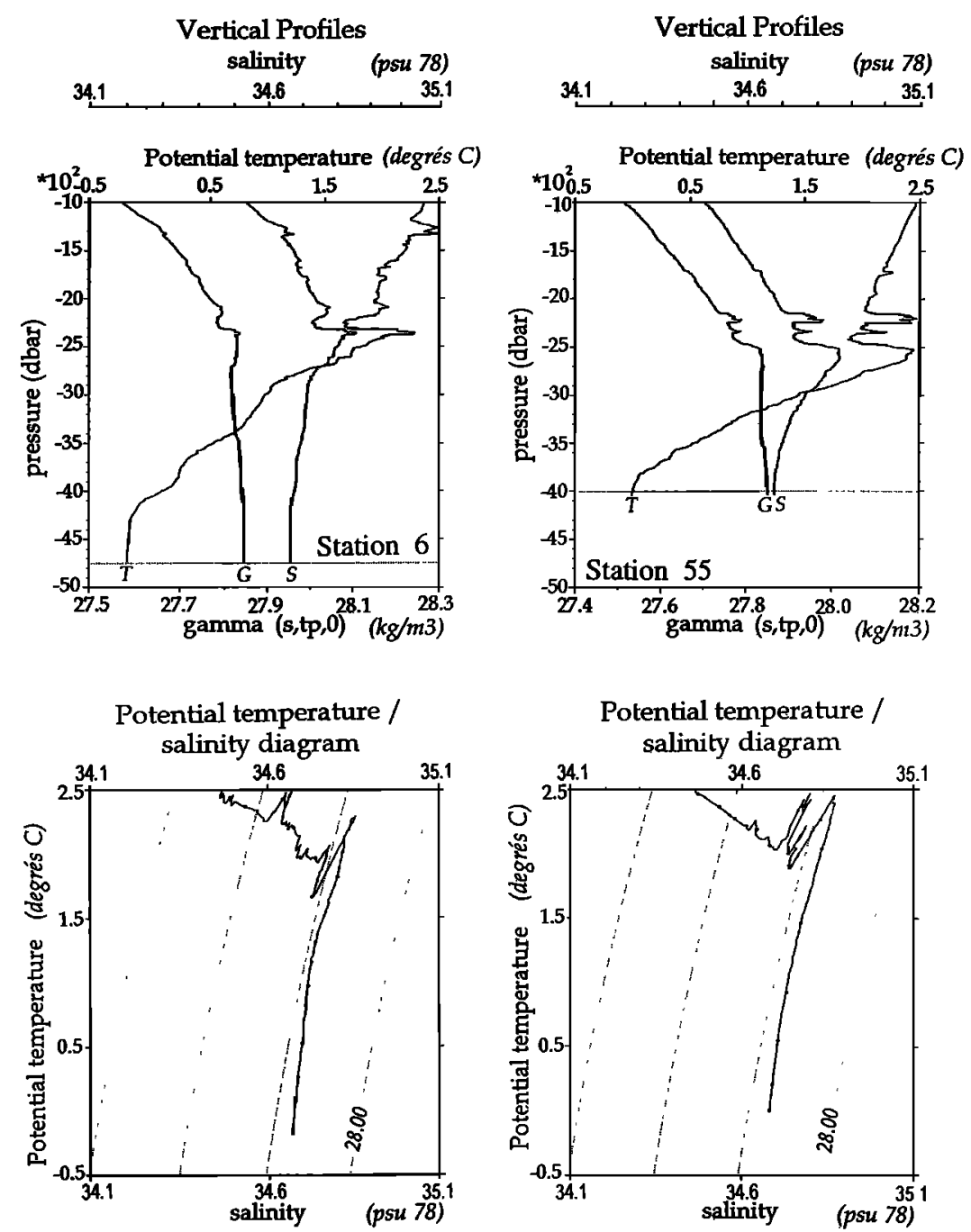

Figure 10a. Temperature and salinity profiles and potential temperature/salinity diagrams at stations 6 and 55.
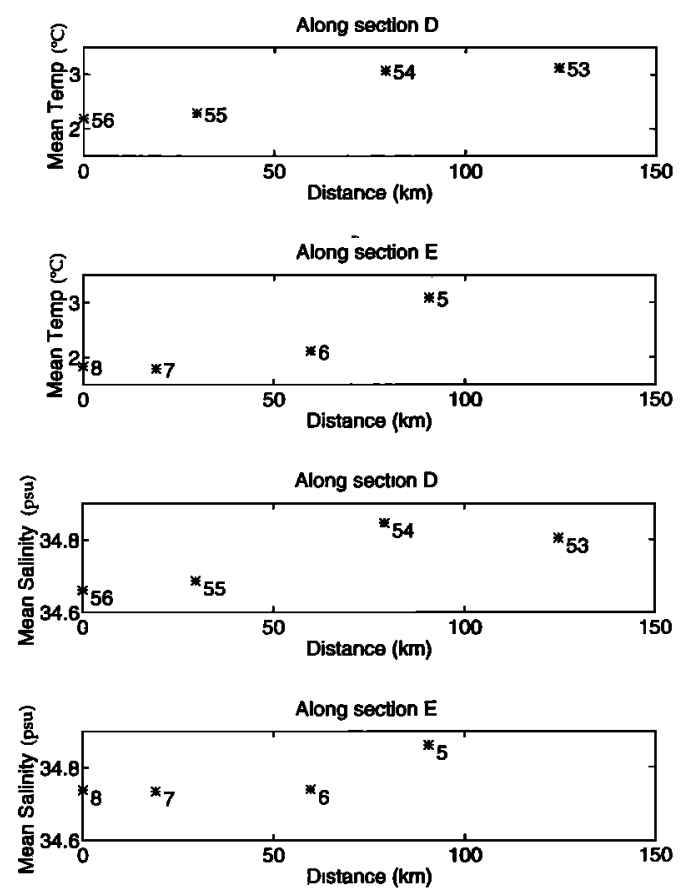

Figure 10b. Vertically integrated $(1500-2500 \mathrm{~m})$ temperature and salinity as a function of distance along sections $D$ and $\mathbf{E}$.
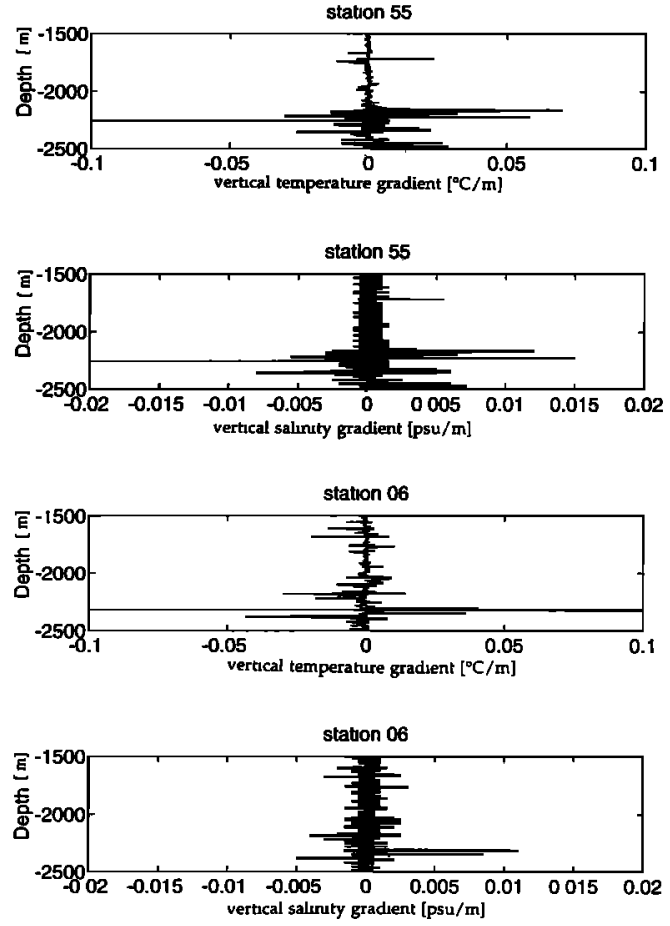

Figure 10c. Temperature and salinity gradients at stations 55 and 6. 

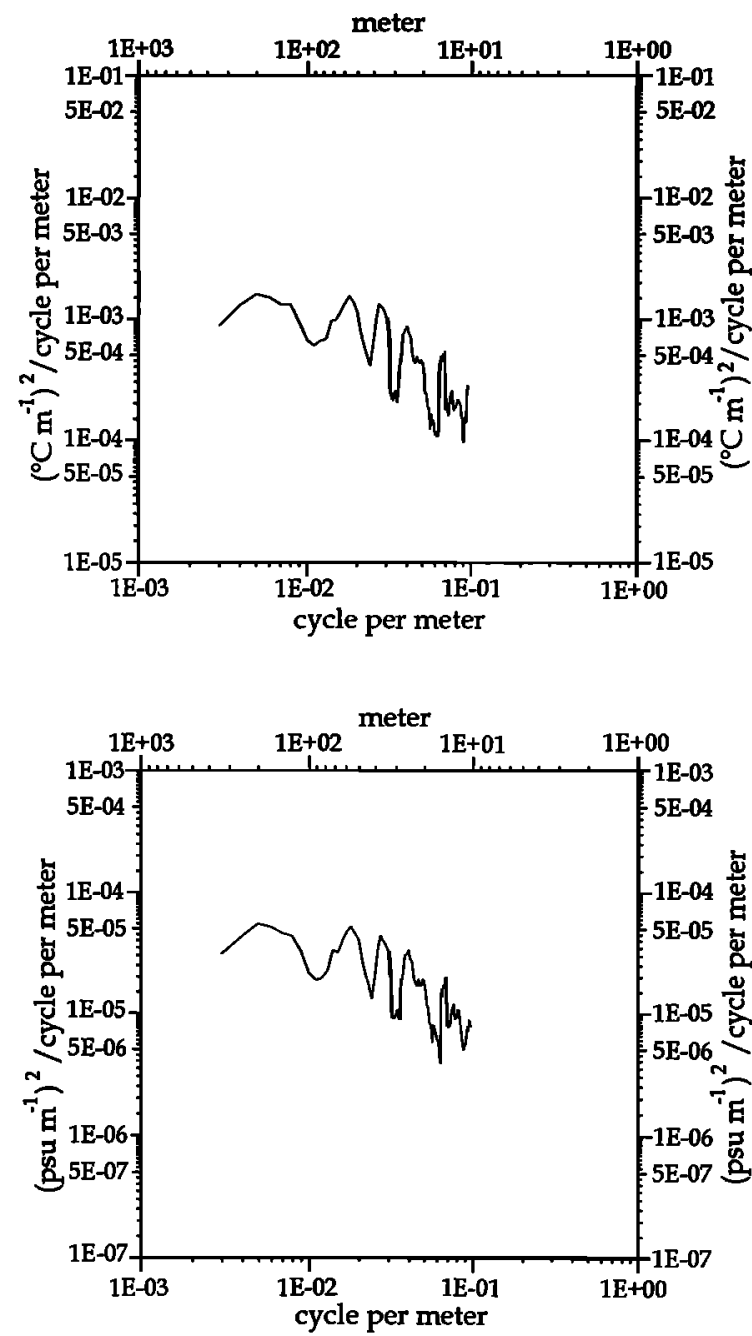

Figure 10d. Spectra of detrended temperature and salinity at station 6.

$10^{-20} \mathrm{C} \mathrm{m}^{-1} \mathrm{~s}^{-1}$ and $1 \times 10^{-3} \mathrm{psu} \mathrm{m} \mathrm{m}^{-1}$ for the lateral temperature and salinity fluxes across the B-M front. Those values are 1 order of magnitude greater than available estimates for other frontal regions.

The following two types of mode waters are observed: STMW on sections $B$ and C and SAMW on all sections. STMW are formed in winter north of the subtropical front, so we are observing remnant patches from winter convection. The SAMW are observed on every section, and two sections (C and D) show two different types of SAMW; one to the west and the other to the east. The T, S, $\mathrm{O}_{2}$, and $\sigma_{t}$ characteristics of the different patches suggest a recirculation of the SAMW. Relatively new SAMW (of type B, following the definition of Piola and Gordon [1989] flows northward along the continental slope until section $C$; i.e., $37^{\circ} \mathrm{S}$. Between sections $\mathrm{C}$ and $\mathrm{D}$ it detaches from the coast and continues northward, crossing the TW/AAIW frontal region where it is strongly altered. Section $B$ is close to its northernmost extension. Then it is entrained southward with the Malvinas return flow and the Brazil Current extension. As it progresses southward, it continues to mix with the TW of the Brazil Current extension, losing oxygen while gaining salinity.

The Confluence 3 hydrographic survey does not extend too much over the deep ocean. However, it provides a good description of the CDW/NADW system near the western boundary. On the three northern sections the UCDW/ NADW/LCDW system is well defined; NADW separates the CDW into two branches of UCDW and LCDW. On the three southern sections, NADW has already left the coast and is easily seen in small patches to the east of the $4000-\mathrm{m}$ isobath. The CDW is wedged between the continental slope and the patches of NADW. The CDW is altered by the NADW as it progresses north, in particular, the UCDW becomes richer in oxygen. Only the water along the slope appears affected by the mixing. The UCDW characteristics at the most offshore station of section A are similar to those of section $F$, i.e., is before the mixing with NADW. The mixing of the remnant patches of NADW with the CDW creates important fine structure in sections $D$ and $E$. This vigorous mixing leads to horizontal heat and salinity fluxes of the order of $5 \times$ $10^{-3 \circ} \mathrm{C} \mathrm{m}^{-1} \mathrm{~s}^{-1}$ and $2 \times 10^{-3} \mathrm{psu} \mathrm{m}^{-1} \mathrm{~s}^{-1}$. Those estimates are an order of magnitude greater than previous ones in the region.

Acknowledgments. We are thankful to Lien Hua, Dédé Billant, and Catherine Maillard for their continuous support and Claude Richez for critical reading of the manuscript. The help of Annie Kartavtseff and Jean Distrophe for the drawings is greatly appreciated. We thank all the participants of the cruise and, in particular, the whole crew from the N.O. LE SUROIT and our Argentinean colleagues, Alejandro Bianchi and Ana-Paula Osiroff. This work is a contribution to the WOCE-France program. We acknowledge support from the PNEDC (Programe National D'Etude du Climat) and from CNRS-INSU (Centre National de la Recherche ScientifiqueInstitut National des Sciences de l'Univers).

\section{References}

Bianchi, A., C. Giulivi, and A. Piola, Mixing in the Brazil-Malvinas Confluence, Deep Sea Res., Part I, 40, 1345-1358, 1993.

Confluence Group, Confluence 1988-1990: An intensive study of the Southwestern Atlantic, Eos Trans. AGU, 71(41), 1131-1134, 1990.

Garçon, V., M. Boulahdid, K. Maamaatuaiahutaipu, and B-Y Boudjellal, Données de sels nutritifs des campagnes Confluence 1, Confluence 2 et Confluence 3, Internal Rep. UMR 39/GRGS 91.103, Groupe de Rech. de Geod. Spatiale, Grasse, France, 1991.

Garrett, C., Mixing in the ocean interior, Dyn. Atmos. Oceans, 3, 239-265, 1979.

Georgi, D. T., Fine structure in the Antarctic polar front zone: Its characteristics and possible relationship to internal waves, $J$. Geophys. Res., 83, 4579-4588, 1978.

Georgi, D. T., On the relationship between the large-scale property variations and fine structure in the Circumpolar Deep Water, Deep Sea Res., 86, Part A, 6556-6566, 1981.

Gordon, A. L., South Atlantic thermocline ventilation, Deep Sea Res., Part A 28A, 1239-1264, 1981.

Gordon, A. L., Brazil-Malvinas confluence-1984, Deep Sea Res., Part A, 36, 359-384, 1989.

Greengrove, C. L., Thermohaline alterations of the South Atlantic pycnocline, Ph.D. thesis, 211 pp., Columbia Univ., New York, 1986.

Joyce, T. M., Large scale variations in small scale temperature/ salinity fine structure in the main thermocline of the Northwest Atlantic, Deep Sea Res., 23, 1175-1186, 1976.

Joyce, T., A note on the lateral mixing of water masses, J. Phys. Oceanogr., 7, 626-629, 1977.

Joyce, T. M., W. Zenk, and J. M. Toole, The anatomy of the Antarctic Polar Front in Drake Passage, J. Geophys. Res., 83, 6093-6113, 1978.

Legeckis, R., and A. L. Gordon, Satellite observations of the Brazil and Falkland currents-1975 to 1976 and 1978, Deep Sea Res., Part A, 29, 375-401, 1982.

Mackas, D. L., K. L. Denman, and A. F. Bennett, Least squares 
multiple tracer analysis of water mass composition, J. Geophys. Res., 92, 2907-2918, 1987.

Mammatuaiahutapu, K., V. Garçon, C. Provost, M. Boulahdid, and A. P. Osiroff, Brazil-Malvinas Confluence: Water mass composition, J. Geophys. Res., 97, 9493-9505, 1992.

Mammatuaiahutapu, K., V. Garçon, C. Provost, M. Boulahdid, and A. Bianchi, Spring and winter water mass composition in the Brazil-Malvinas Confluence, J. Mar. Res., 52, 397-426, 1994.

Martineau, D. P., The influence of the current system and lateral mixing upon Antarctic Intermediate Water in the South Atlantic, Ref. Publ. 53-72, Woods Hole Oceanogr. Inst., Woods Hole, Mass., 1953.

McCartney, M. S., Subantarctic Mode Water, in A Voyage of Discovery, Deep Sea Res., 24, supplement, 103-119, 1977.

McCartney, M. S., The subtropical recirculation of Mode Waters, $J$. Mar. Res., 39, 267-293, 1982.

Millard, R. C., W. B. Owens, and N. P. Fofonoff, On the calculation of the Brunt-Văisälä frequency, Deep Sea Res., Part A, 37, $167-181,1990$.

Molinelli, E. J., The Antarctic influence on Antarctic Intermediate Water, J. Mar. Res., 39, 267-293, 1981.

Piola, A. R., and D. T. Georgi, Circumpolar properties of Antarctic Intermediate Water and Subantarctic Mode Water, Deep Sea Res., Part A, 29, 687-712, 1982.
Piola, A. R., and A. L. Gordon, Intermediate waters in the southwest South Atlantic, Deep Sea Res., Part A, 36, 1-16, 1989.

Provost, C., L. Mémery, and B. Torres Lista, Confluence 3, Données CTDO2, Internal Rep. LODYC 91/02, Lab. d'Océanogr. Dyn. et de Climatol., CNRS, Univ. Pierre et Marie Curie, Paris, 1991.

Reid, J. L., W. D. Nowlin, and W. C. Patzert, On the characteristics and circulation along the southwestern Atlantic Ocean, J. Phys. Oceanogr., 7, 62-91, 1977.

Roden, G., Thermohaline fronts and baroclinic flow in the Argentine basin during the austral spring of 1984, J. Geophys. Res., 91, 5075-5093, 1986.

Wüst, G., The Stratosphere of the Atlantic Ocean, p. 1978, translated and edited by W. Emery, Amerind, New Delhi, 1935.

M. England, V. Garçon, and K. Maamaatuaiahutapu, Centre National de la Recherche Scientifique, UMR 39, GRGS, 18 avenue Edouard Belin, 31055 Toulouse Cedex, France.

S. Gana and C. Provost, Centre National de la Recherche Scientifique, LODYC, Université Pierre et Marie Curie, 4 Place Jussieu, 75252 Paris Cedex 05, France. (e-mail: cp@ares.lodyc.jussieu.fr)

(Received November 16, 1993; revised May 2, 1994; accepted August 22, 1994.) 